\title{
G-Quadruplex Targeting Ligands: a Hope and a New Horizon in Cancer
}

\section{Therapeutics}

\author{
Nilanjan Banerjee, Suman Panda and Subhrangsu Chatterjee* \\ Department of Biophysics, Bose Institute, P-1/12 CIT Road, Scheme VIIM, Kankurgachi, Kolkata, Pin-700054, \\ India
}

\begin{abstract}
:
G-quadruplex, a unique secondary structure in nucleic acids found throughout human genome elicited widespread interest in the field of therapeutic research. Being present in key regulatory regions of oncogenes, G-quadruplex structure regulates transcription, translation, splicing, telomere stability etc. Changes in its structure and stability lead to differential expression of oncogenes causing cancer. Thus, targeting G-Quadruplex structures with small molecules/ other biologics has shown elevated research interest. Covering previous reports, in this review we try to enlighten the facts on the structural diversity in G-quadruplex ligands aiming to provide newer insights to design first-in-class drugs for the next generation cancer treatment.
\end{abstract}

Keywords: G quadruplex, Oncogene, ligand, cancer

\section{Introduction:}

G-quadruplex (G4) are one of the several non-canonical structures of nucleic acid. These are formed in stretches of DNA which are rich in guanine bases and is located throughout the entire genome. Computational estimates propose that sequence motifs of the type $\mathrm{G}_{23} \mathrm{~N}_{1-7} \mathrm{G}_{23} \mathrm{~N}_{1}$ $7 \mathrm{G}_{\geq 3} \mathrm{~N}_{1-7} \mathrm{G}_{\geq 3}$ in the human genome have the potential to form a G-quadruplex structure ${ }^{1-3}$. Generally, four Guanines arrange in a square planar fashion bonded through cyclic Hoogsteen hydrogen-bond to form a G-quartet. Typically, three or four such quartet stack upon one another separated by loops of varying length using $\pi-\pi$ base stacking interaction to form a G4 
structure (Figure1). They are further driven by presence of monovalent cations like $\mathrm{K}^{+}, \mathrm{Na}^{+}$ etc $^{3}$.

There are number of stabilizing factors that stabilizes a G-quadruplex structures namely, base stacking, hydrogen bonding, hydration structure, and electrostatic interactions. Apart from this the central cavity accommodates a cation which negates the incoming repulsive forces due to charges from the guanine O6 carbonyl groups. Calculations exhibited the energy for an average hydrogen bond increases from 0.22 to $0.42 \mathrm{eV}$, when involved in the G-quartet establishment ${ }^{4}$. This substantial surge in binding energies was credited to resonance-assisted hydrogen bonding ${ }^{4}$. The $\mathrm{N} 2, \mathrm{~N} 3$ and $\mathrm{O} 4$ of the guanine tetrad remains associated with water molecule further stabilizing G-quadruplex giving rise to hydration ordered structures. The bases of DNA are non-polar in nature thus they stack upon one another to reduce the area exposed to polar solvent. They are then acted upon by hydrophobic, electrostatic and van der walls force to provide stability. Further both telomeric and non-telomeric quadruplexes are bound by a wide array of proteins which either stabilizes or destabilizes them.

Still all these interactions are not enough to stabilize the G-quadruplex structures. Since in most of the cancer the G-quadruplex gets destabilized ${ }^{5}$, developing ligands that specifically stabilizes the G-quadruplex structures is a frontier research area in biology and chemistry. The ability of small molecules to stabilise G-quadruplex DNA and interfere with telomere extension in cancer cells by inhibiting the enzyme telomerase have highlighted the potential role of quadruplexes as anti-cancer drug targets ${ }^{6}$. In this review we will discuss the important ligands that are currently used to target different G-quadruplex structures.

\section{Distribution and function of the G-quadruplex in-vivo}


Thirty years ago, Aaron Klug made a statement about the in vivo existence of G-quadruplex scaffolds: "If G-quadruplexes form so readily in vitro, nature will have found a way of using them in vivo". Bioinformatics analysis has predicted that human genome has $\sim 700,000$ putative G-quadruplex forming sequences (PGQS) ${ }^{7}$. The interesting fact is these structures are not at all randomly located rather they are significantly associated with some key regulatory areas like telomere, replication origin, promoter, 5'-UTR and 3'-UTR, Ribosome binding sites (RBS) and in long non-coding RNA where they modulate gene expression suggesting that G4 structures may play a pivotal role in the control of a variety of cellular processes. Quadruplex located in promoter generally have an inhibitory effect to the gene expression, whereas those in 5'-UTR and 3'-UTR generally modulates translation $^{8}$, miRNA binding ${ }^{9}$, pre-mRNA splicing $^{10}$, alternate polyadenylation ${ }^{11}$ and mRNA targeting ${ }^{8}$. Strikingly, these structures are often present in proto-oncogenes and apparently absent in tumour suppressor genes, which suggests evolutionary selection for G-quadruplex structures based on their function ${ }^{12,13}$.

These PGQS were first identified within human telomeric DNA. The structure and stability of telomeres are closely related to cancer ${ }^{14}$, aging ${ }^{15}$, and genetic stability. G4 in telomeres acts as tumor suppressor by inhibiting telomerase thereby maintaining the telomere ${ }^{16-18}$. Telomeric quadruplexes are highly conserved and are associated with numerous telomeric proteins ${ }^{19}$.

Studies led by Picard et al found that almost $80 \%$ of replication origins overlaps with a $\mathrm{PGQS}^{20}$. G4 structures are also formed during replication acting as 'roadblocks' and impede replication fork progression ${ }^{21}$ (Figure 2). Evidence came from the loss-of-function mutation of DOG1 gene (FNACJ helicase) known to resolve quadruplex structures ensuing in hoarding of $\sim 50-300$ nucleotide upstream of potential G-quadruplex motifs ${ }^{22}$. Certain G4 structures also play a positive role in replication initiation. Research by Valton et al pointed to the fact that deletion of G4 motifs in med14 origin led to the dramatic decrease in replication origin 
activity $^{23}$ also point mutation in consensus G4 motif $\beta^{\mathrm{A}}$ led to much lower replication origin activity compared to wild type cell ${ }^{23}$.

In-silico studies exposed the fact that G4 motifs are mostly clustered in promoter regions of almost 20,000 genes ${ }^{24}$. Several oncogenes like $c-M Y C^{25}, B C L 2^{26}, c-K I T^{27}, K-R A S^{28}, V E G F^{29}$, $R B^{30}, P D G F-A^{31}, h T E R T^{32}$, etc harbours a putative stable $\mathrm{G} 4$ structure $1 \mathrm{~kb}$ of each side of Transcription start site $(\mathrm{TSS})^{33}$. In most of these cases the PGQS acts as a transcription repressor thereby maintaining a threshold level of transcript of the gene (Figure 2). Studies have shown that stabilization of G4 structure in NHEIII 1 results in decreased expression of the $c-M Y C$ transcription. Similarly, the guanine rich strand on the proximal promoter region of the $V E G F$ gene regulates its expression. Stabilization of this G4, downregulates the VEGF expression $^{34}$. Ribosome biogenesis, occurring in nucleolus, is meticulously controlled by multiple cell signalling pathways and the quadruplex in non-template strand ${ }^{35}$. Synthesis of rRNA is the rate limiting step of ribosome biogenesis. There are two G4 - NUC 19P and NUC $23 \mathrm{P}$ - present in the ribosomal DNA (rDNA) ${ }^{36}$, which controls the rate of synthesis of rRNA. Formation and stabilization of these quadruplex by nucleolin protein results in overexpression of rRNA ${ }^{37}$. Here quadruplex acts as a transcriptional activator.

There are several other examples which corroborates to the fact that G-quadruplexes are key regulatory checkpoints inside the cell. Genome-wide-survey of G4 motifs across several species has concluded that they are evolutionary conserved ratifying their important functional role in biology ${ }^{12,38}$.

After the evidence of the in-vivo existence of G-quadruplexes was established using specific antibodies against parallel and antiparallel G-quadruplexes formed in telomeric DNA of the ciliate Stylonychia lemnae ${ }^{39}$, directive and quantitative visualization of DNA G-quadruplex structures in mammalian cells was recently reported ${ }^{40}$. With structure-specific antibody BG4, 
the G-quadruplex was visualized forming in telomeres and outside of telomeres and formed in a replication-dependent manner in the cell cycle. More importantly, the increased BG4 foci number was observed after treatment with the G-quadruplex binding ligand, indicating that the small molecule could trap and stabilize a G-quadruplex in human cells ${ }^{40}$. In addition, the practical high-throughput DNA sequencing showed the significant co-localization of G4s with antibody $1 \mathrm{H} 6^{41}, \mathrm{BG} 4^{40}, \mathrm{hf} 2^{42}, \gamma \mathrm{H} 2 \mathrm{AX}^{43}$ and DEAH/RHA family of helicases ${ }^{44}$. All these substantial evidences not only provide for the existence and location of G4s in the genome but also implicate the profound function of G-quadruplexes. A specific small molecule could modulate these structures in cells, which strongly supports the therapeutic potential of targeting a G-quadruplex.

\section{Modes of G-quadruplex-Ligand Interaction}

From the example shown above it is clear that presence of G-quadruplex in and around key oncogenes makes it a suitable site for drug targeting. There are many ligands which binds to G-quadruplex either to stabilize or destabilize it. G-Quadruplexes have several interaction sites. Since true intercalation (opening of the two quartet to incorporate a planar molecule) is not possible, end stacking is more preferred mode of binding, as it does not require the transient unstacking of G-quartet ${ }^{45}$. Several ligands rather than binding to pre-formed quadruplex facilitates the guanine rich region to fold to quadruplex. Kinetic study has led to the better understanding of the mechanism of these events. A perylene derivative called PIPER (Figure 5) is an example of such compound which promotes the folding of telomeric sequence TTAGGG to dimeric and tetrameric $\mathrm{G} 4 \mathrm{~s}^{46}$. Generally, most of the ligands possess similar chemical structure namely planar aromatic ring and charged side chain. The G-quadruplex forms an ideal platform where ligand can bind with $\pi-\pi$ stacking. Some exploit the groove 
formed by the backbones and bind to the G4, which mainly include the terminal G-tetrads, the middle G-tetrads, the grooves/loops/backbones, and the central channel. Ligands with planar aromatic rings interact with the G-quadruplexes mainly through $\pi$ - $\pi$ stacking on the terminal G-tetrads and less through intercalating into the G-tetrads ${ }^{47-49}$. Ligands containing amino groups and (or) side chains can interact with the grooves, loops, and the negatively charged phosphate backbone of the $\mathrm{G} 4 \mathrm{~s}^{50,51}$. The amino groups become positively charged by protonation or methylation, which may result in better recognition and stronger binding to the grooves as well as to the negatively charged phosphate backbone through electrostatic interactions ${ }^{52,53}$. The side chains can recognize the loop bases and grooves by forming hydrogen bonds, which also improves the water solubility of the ligands. More interesting is that small-sized ligands with long positively charged side chains can lie at the central channel of a G-quadruplex, which in turn leads to an increase in the stabilization of the G-quadruplex. Research has indicated that although planar ligands can insert into the G-tetrad layers, charged molecules are more inclined to interact with the grooves, loops or backbones of $\mathrm{G}$-quadruplex structures $^{53,54}$.

\section{Diversity of G-quadruplex interactive ligands}

\section{(A) Oncogene specific ligand}

Now a days supressing the expression of an oncogene or developing an inhibitor for a particular protein is an effective way to treat cancer. But it is not full proof method as the inhibitors is not that selective and it binds to other proteins having sequence similarity. At this juncture quadruplex comes to rescue as they are a perfect target for drug/ligands as certain vital oncogenes harbour a quadruplex in them which regulates their expression. Thus, developing molecule with high drug-likeness and G4 specificity is the key to generate next-gen anti-cancer drug. In this section we discuss some crucial oncogenes that are found to be most over- 
expressed across all types of tumor and cancer and ligands that are specific to those oncogenic quadruplexes.

\section{Telomere}

Telomere protects the chromosome end from shortening and regulates senescence and apoptosis $^{55}$. Telomerase, a telomeric G4 binding protein, plays a key role in tumorigenesis ${ }^{56}$. This, together with the fact that telomerase is over-expressed in $>85 \%$ of all tumors and across all tumor types, suggest that embarrassment of telomerase would be an operative anticancer therapeutic tactic ${ }^{57}$. Since telomerase binds to telomeric G4, the later becomes a fine druggable target for cancer treatment. The most well studied ligand that was first developed against telomere G4 to inhibit telomerase was the N,N'-(9-((4(dimethylamino)phenyl)amino)acridine-3,6-diyl)bis(3-(pyrrolidine-1-yl)propanamide), or BRACO-19 (B19) (Figure 2) in short. The specification of B19 to G4 is due to an acridine core and a nitrogen atom in the heterocyclic frame that could be protonated at physiological environments ${ }^{50}$. As a result, the electron deficiency in the chromophore was amplified, with subsequent boost of the G4 interaction ${ }^{58}$. These classes of compounds muddle to G4 via $\pi-\pi$ interaction and additionally requests tertiary amine groups, since it is protonated at physiological $\mathrm{pH}$, in their side chain to interact with the grooves ${ }^{59}$. Telomestatin is another naturally occurring compound that binds most tightly to the telomeric G4. Though it has an $\mathrm{EC}_{50}$ value of $5 \mathrm{nM}$, research by Anne De Cian and colleagues show that it might not be that potent as it was claimed ${ }^{60}$.

\section{hTERT}

As mentioned earlier, the transcriptional instigation of this telomerase reverse transcriptase ( $h T E R T)$ gene is crucial during tumorigenesis, its expression remains repressed in adult somatic 
cells $^{61}$. Thus, the expression of $h T E R T$ gene is highly regulated by several transcription factors as well as epigenetic state. It also harbors a G4 structure in its core promoter which regulates the expression of the catalytic subunit of the telomerase ${ }^{62}$. Mutations in the hTERT promoter has been reported in $>75 \%$ of glioblastomas, melanomas ${ }^{63,64}$ and in aggressive thyroid cancer ${ }^{65}$ and most importantly all these mutations are found to be in the G-rich region which forms quadruplex $^{32}$. Metastasis suppressor non-metastatic 2 (NME2) and RE1-silencing transcription factor (REST)-lysine-specific histone demethylase 1 (LSD1) co-repressor complex associates with the G4 in $h T E R T$ promoter to repress the expression of telomerase ${ }^{61}$. In most of the cancer the hTERT G4 gets resolved to duplex DNA and in absence of G4 structure the NME2 and REST co-repressor complex fails to bind to the promoter resulting in the high level of telomerase expression leading to cancer and tumorogenesis. So technically stabilizing the hTERT G4 in cancer cell seemed to be novel therapeutic avenue. On treating with eleven G4 specific ligands $\sim 50-85 \%$ downregulation of $h T E R T$ is seen in HT1080 cells (Figure 2) ${ }^{61}$. But the problem is these ligands are not hTERT G4 specific ligand rather they bind to any G4 structures. Gomez et al developed a 2,4,6-triamino-1,3,5-triazine derivatives, ligand 12459, a potent G4 stabilizer present in $h T E R T$ intron $6^{66}$ (Figure 3). It downregulates the expression of telomerase by altering the $h T E R T$ splicing pattern, thereby reducing the expression of active $(+\alpha+\beta)$ transcript and over-express inactive $(-\beta)$ transcript. 12459 induces the guanine rich region present in the $5^{\prime}$ end of intron 6 of $h T E R T$ to form quadruplex ${ }^{66}$. It is also more specific to hTERT G4 than telomeric quadruplex. Compared to telomestatin and B19, 12459 was found to be more potent in achieving 50\% inhibition in annealing the Guanine rich strand with its complementary strand. The IC50 value of the reaction was found to be $1.75 \pm 0.37 \mu \mathrm{M}$ for G4TERT1 sequence, which is way less than telomestatin and B19 which had IC50 value of $5.0 \pm 1.7$ and $5.7 \pm 1.1$ respectively ${ }^{66}$. It also induces massive telomeric dysfunction along with DNA damage at $0.5-1 \mu \mathrm{M}$ concentration ${ }^{67}$. Hence to conclude we can assume that 12459 
induces the formation of $\mathrm{G} 4$ structure causing alternative splicing to reduce active telomerase formation. Stabilizing the G4 also allows the NME2 and REST co-repressor complex to bind to it and repress telomerase expression.

\section{$B C L 2$}

Certo et al found that being the central protein to maintain a balance between apoptosis and survival, tumor cells depend upon the BCL2 for their survival ${ }^{68}$. Aberrant expression of BCL2 is also responsible for neurodegenerative disease like Parkinson ${ }^{69}$, Alzheimer's ${ }^{70}$ and multiple sclerosis $^{71}$. There are G-quadruplex located upstream of major promoter P1 of $B C l 2^{26}$. Several organic molecules are reported to bind to $B C L 2 \mathrm{G} 4^{72}$. But they fail to discriminate between BCL2 G4 and other G4 in cell, thereby hampering their advancement as clinical drugs. A derivatives of furo[2,3-d]pyridazin-4(5H)-one (FP3) (Figure 3) could selectively bind to the BCL2 quadruplex and stabilize it; thereby down-regulating the expression and transcription of BCL2 gene ${ }^{73}$. The pyridazinone moiety was selected because of its anti-cancerous, antiinflammatory and anti-thrombotic property ${ }^{74}$. FP3 also was able to discriminate and selectively binds to $B C L 2 \mathrm{G} 4$. It showed substantial cytotoxicity in Jurkat cells with $30 \%$ inhibition at 10 $\mu \mathrm{M}$ concentration and $40 \%$ reduction in Bcl-2 protein on treatment with $25 \mu \mathrm{M}$ for 24 hours. Jana et al. recently confirmed that another quindoline derivative, chelerythrine, interacts with $B C L-2$ G4. Even though it shows higher quadruplex-to-duplex selectivity and induce selective cytotoxicity to varied cancer cells, the molecule is found to interact with telomeric and other oncogenic quadruplexes ${ }^{75}$. 
A triaryl-substituted imidazole/carbazole conjugate, with two 1-methylpiperazine side chains and a phenyl moiety in the imidazole ring, IZCZ-3(Figure 3), can selectively bind $c-M Y C$ Gquadruplex. It was seen that on removing the 1-methylpiperazine side chain the selectivity to c-MYC quadruplex was reduced. The 1-methylpiperazine helps to increase electrostatic interaction and the phenyl moiety reduce its binding affinities with antiparallel or hybrid Gquadruplexes thus focussing it to bind to parallel $c-M Y C$ G-quadruplexes ${ }^{76}$. This ligand has the four-clover leaf like structure which as shown in Figure 3, stacked perfectly on the terminal Gquartet plane of $c-M Y C$ via $\pi-\pi$ interaction, and the positively charged central imidazole moiety was located in the ion channel of the $c-M Y C$ G-quadruplex, leading to a relatively low binding energy of $-8.7 \mathrm{kcal} / \mathrm{mol}^{76}$, thereby showing significant anti-cancer activity by arresting cancer cells at G0/G1 cell cycle. Another molecule 6-methyl-3-(naphthalen-2-yl)-8a-(4methylpyridin-2-yl)-indolizinone(indolizinone) also selectively recognise $\quad c-M Y C \mathrm{G}$ quadruplex in 1:1 binding model ${ }^{77}$. Thus, it was seen that molecule with aromatic group can stack onto the quadruplex and interact strongly ${ }^{77}$.

\section{KRAS}

$K R A S$ is another most frequently mutated yet undruggable oncogene in human cancer. To target KRAS at gene level and develop new therapeutic strategy, one regioisomers of 5-methylindolo[3,2-c]quinoline derivatives (IQc:3e) (Figure 3) with a range of alkyl diamine side chains was designed to target DNA promoter of the KRAS gene. IQc:3e has flat extended heteroaromatic surface that can stack onto G-quartets through $\pi-\pi$ stacking and the basic sidechains can hydrogen bond and establish electrostatic interactions with the phosphate backbone and loops/grooves of G4 DNA, either directly or mediated via water molecules. It was seen that molecules lacking alkyldiamines as their side chain produced lower affinity towards $K R A S$ 
gene. The IQc:3e has IC50 value of $1.8 \mu \mathrm{M}$ and $1.98 \mu \mathrm{M}$ against $K R A S$ dependent colon cancer cell line HCT116 and pancreatic cancer cell line MiaPaCa2 respectively. Whereas it has higher $\mathrm{IC}_{50}$ value for $K R A S$ independent breast cancer cell line $(\mathrm{IC} 50=11.40 \mu \mathrm{M})$ and lung fibroblasts WI-38 cell line $\left(\mathrm{IC}_{50}=10.08 \mu \mathrm{M}\right)$ respectively ${ }^{78}$.

\section{cKIT}

Another gene $c$-KIT is generally involved in diverse biological function namely, maintenance of haematopoetic stem cell, melanogenesis, erythropoiesis, spermatogenesis, etc including cancer $^{79}$. Thus, its dysregulation gives rise to plethora of diseases including cancer. Its gain-offunction mutation is linked to gastrointestinal stromal tumors $(>70 \%)$, mast cell tumors $(>70 \%)$ and some acute myeloid leukemia $(>68 \%)^{80}$. At first tyrosine kinase inhibitor (TKI) was used to treat cancer overexpressing $c$-kit. But soon drug resistant took over and the drugs failed to make impact. Just upstream $c$-KIT transcription start site, there are two G4 forming element, KIT1 and KIT2, regulating the $c$-KIT expression and hence they offer an excellent target for drug. Two anthraquinone derivative with (AQ1) and without (AQ7) phenylalanine moiety in its side chain was found to selectively bind to the $c$-KIT G4. The binding affinity drastically reduced on removing the phenylalanine moiety. Based on Alamar Blue cytotoxicity test, AQ1 (Figure 3) was found to have an $\mathrm{IC}_{50}$ value of $1.65 \mu \mathrm{M}$ and 3.00 $\mu \mathrm{M}$ for HCG27 and MCF7 cells respectively ${ }^{80}$. Whereas AQ7, being a better $c$-KIT quadruplex binder, showed meagre to no cytotoxicity. This is could be due to the inability of AQ7 in reaching intracellular target due to its large side chain. This proves that affinity always does not corresponds to cytotoxicity. Another derivative of indenoisoquinolines (ISb) also selectively targeted $c$-KIT G4. Previously indenoisoquinoline derivatives have revealed antiproliferative properties in several human cancer cell lines $^{81,82}$. ISb particularly stabilized KIT1 G4 having IC 50 value of $4.1 \pm 0.43 \mu \mathrm{M}$ and 
$0.3 \pm 0.034 \mu \mathrm{M}$ in $c$-KIT overexpressed Gastrointestinal stromal tumor GIST882 cell line and colorectal cancer cell line HT-29 respectively ${ }^{83}$.

\section{$r D N A$}

In genome perhaps, the densest population of $\mathrm{G} 4$ after telomere is present in rDNA having $12 \%$ more G4 than rest of the genome ${ }^{84}$. There are approximately $1500 \mathrm{G} 4$ motifs in rDNA nontranscribed strand that act as transcription activator ${ }^{84}$. RNA Polymerase I complex (Pol I) is responsible for transcription of rRNA genes and as a result control ribosome biogenesis. Studies by Merenzini et al have found that in cancer the Pol I activity and rRNA synthesis is remarkably high ${ }^{85}$. Nucleolin stabilizes these G4 structure and enhances the activity of Pol I, to synthesise more rRNA ${ }^{86,87}$. Thus, this nucleolin/G4 complex offers a potential therapeutic target to treat cancer. A fluoroquinolone derivative called quorfloxin (Figure 3) have been developed which targets and disrupts nucleolin/G4 complex inducing apoptosis in cancer cells. This is the first molecule to go to Phase II clinical trial ${ }^{37}$. It is selective in disrupting rRNA synthesis and does not inhibit DNA or protein synthesis. It has an $\mathrm{IC}_{50}$ value of $3.3 \mu \mathrm{mol} / \mathrm{L}^{87}$. This molecule is highly selective and kills cancer cells associated with over-expressive ribosome biogenesis. It does not hamper cellular effects associated with other G4 structures of other oncogenes. Quorfloxin is also resistant to multi drug resistant and hence has been developed as a key therapeutic molecule.

\section{VEGF}

Vascular endothelial growth factor (VEGF) plays a pivotal role for tumor angiogenesis by stirring the growth, migration, survival and permeability of endothelial cells thereby causing metastases. There are several VEGF targeting drugs available in market such as bevacizumab $^{88,89}$ sorafenib $^{90}$ etc. The $V E G F$ promoter contains a guanine rich region which 
can fold to G4 structure and provides a platform for binding of multiple transcription factor such as sp1, Ap2 and Egr $1^{34}$ to regulate VEGF expression at transcriptional level. This calls for a novel methodology for rational drug design targeting VEGF quadruplex. Yuе Wu synthesized quindoline derivatives and introduced 5-N-methyl and 7-fluoro groups to augment its interaction with the VEGF G-quadruplex DNA. The IC50 of SYUIQ-FM05 (Figure 3) was found to be $1.0 \pm 0.4 \mu \mathrm{M}$ which is much lower compared to its parent molecule SYUIQ-05 $\left(\mathrm{IC}_{50}=16.6 \pm 0.7 \mu \mathrm{M}\right)^{91}$. Electron donating alkyl group, Fluorine and N,N-dimethylpropane1,3-diamine side chain thus made it more potent and VEGF specific drug. The positive charge in the $5-N$-position contributes to electrostatic interaction and improves the $\pi-\pi$ stacking to quadruplexes. The alkyl amino group at the 11-position increases basicity of the quinolone nitrogen, which allows in situ protonation of the $5-\mathrm{N}$-atom at physiological $\mathrm{pH}$ and the cationic ligand core to contact the negatively polarized quartet centre. Further VEGF transcription was suppressed dramatically at $0.5 \mu \mathrm{M}$ concentration. But it also targets $c-K I T$ and $B C L-2 \mathrm{G} 4$, thus lacks selectivity ${ }^{91,92}$.

\section{(B) Classification based on backbone}

\section{Anthraquinone derivatives}

In 1997, Neidle and Hurley group reported the first quadruplex-interactive ligands as a telomerase inhibitor molecule i.e. 2,6-Diaminoalkylamido-anthraquinone, BSU-1051 (Figure 4) with a telomerase $\mathrm{IC}_{50}$ of $23 \mu \mathrm{M}^{93}$. From there on, wide range of the disubstituted amidoanthraquinone family such as 1,4-, 1,5-, 2,6-, and 2,7- isomers were developed with substituents at various positions on the chromophore and by changing side chain length and size, and the nature of the side chain terminal groups were modified by systemic structurefunction studies. Molecular modelling studies showed that anthraquinone compounds bind to 
G4 by a 'threading intercalation' mode with $\pi-\pi$ overlapping, where any flexible side chains can protrude into wider grooves of G4 and same binding mode is also observed for dsDNA too. Therefore, these compounds are not that much selective and specific for quadruplex DNA and thus their cytotoxicity can be high.

To reduce the cytotoxicity, a carbonyl group was removed from the anthraquinone moiety, a series of disubstituted 2,7-amido-fluorenones(2,7-FO) were designed and synthesized by removing a carbonyl group from the anthraquinone moiety thus preventing redox cycling ${ }^{94}$. These 2,7-FO derivatives has less telomerase $\mathrm{IC}_{50}$ values of $8-12 \mu \mathrm{M}$ with upto 10 fold reduced cytotoxicity, compared with that of their parent anthraquinone derivatives in different human cancer cell lines. This slighty less telomerase activity of 2,7-FO derivatives with that of parent molecule is due to decreased electron deficiency in the chromphore and the curved scaffold which is not favourable for pi-stacking interaction with G4 structures ${ }^{94}$.Tetracyclic anthraquinone analogues with another heterocycle attached to the anthraquinone core in place of side chains were reported and these compounds show anti-telomerase activity, because they also interact with G-quadruplex. For benzonaphtho-furan compounds, modifications of tricyclic anthraquinones to tetracyclic derivative are also synthesized. Molecular models showed that tetracyclic compounds provide more surface area suitable for stacking interaction with G-quartet.

\section{Acridine derivatives}

Chromophore containing positively charged central ring has been extensively used for designing G4 binding ligands as the positively charged ring is likely to be complementary to the channel of G-quadruplexes with negative electrostatic potential. Thus,to overcome the problem of the specificity and selectivity of anthraquinones for quadruplex DNA and duplex 
DNA, Neidle and his groups modified the acridine core and its side chains by introducing a pyridine ring in the ligand core in place of quinine which increase the positive charge of the ligand core thus enhancing the electrostatic interaction with the negatively charged G-quartet channel ${ }^{95}$. They synthesized a series of 3,6-disubstituted acridines including BSU 6039 (Figure $5)^{96}$. But these compounds failed to increase telomerase inhibition probably because of the insufficient basicity of the pyridine ring nitrogen. Based on $\mathrm{X}$ ray crystal structures and molecular modelling study of the complex between telomeric G4 and BSU 6039, disubstituted acridines are further modified by replacing the core with acridone, changing the substitution pattern, by the use of polyamine and a variety of 3,6,9-trisubstituted acridines were synthesized ${ }^{97}$. The basicity of the pyridine ring nitrogen is increased by the incorporation of the anilino group at the 9-position, allowing the ligand core to be protonated at physiological $\mathrm{pH}$ and this provides an additional interaction with the third groove. Two side chains at 3- and 6-positions were subjected to the two widest grooves. 3,6,9-Trisubstituted acridines analogues have much stronger binding affinity and specificity for quadruplex DNA over duplex DNA (10-70-fold greater binding constants), whereas 3,6- disubstituted acridines have similar binding constants for duplex and quadruplex DNA. BRACO-19, being a member of 3,6,9trisubstituted acridines, showed very high binding affinity for quadruplex DNA over duplex DNA and high anti-telomerase activity in range of $10-20 \mathrm{nM}^{98}$. Further study showed that BRACO-19 also has antitumor activity in human xenografts ${ }^{99}$. Stevens et al. reported that the $\mathrm{N}$-methylated pentacyclic acridinium salts are another class of pentacyclic acridine derivatives. RHPS4, a pentacyclic acridine 3,11-difluoro-6,8,13-trimethyl(8H)-quino[4,3,2-kl] acridinium methylsulfate (Figure 5), one such compound under this class, exhibit telomerase inhibitory activity ( ${ }^{\mathrm{tel}} \mathrm{IC} \mathrm{C}_{50} 0.33 \mu \mathrm{M}$ by TRAP assay) and inhibit cell proliferation within $2-3$ weeks at noncytotoxic concentrations $^{100}$. This high activity is due to the strong electrostatic interaction between the positively charged ligand core, containing methylated quaternary nitrogen and 
negatively charged quadruplex centre. However, this small size aromatic compound can also intercalate into duplex DNA with modest selectivity. Based on the finding that oxidized riboflavin binds to an intramolecular G-quartet with moderate affinity trisubstituted isoalloxazines were also synthesized. These compounds are not that much selective against duplex but some trisubstituted isoalloxazines were found to be approximately 15 -fold more selective for quadruplex found in the c-kit promoter than that of telomeric $\mathrm{G} 4^{100}$. This result indicates that coplanar tricyclic drug like small molecules can easily selectively bind to G4 over duplex DNA. Recent studies have shown that simple anthracenes with tethered side chains at appropriate positions can also act as selective G-quadruplex ligands.

\section{Bis-aryl Compounds}

Bis aryl compounds are one of the most extensively used G4 stabilizing ligand. These compounds contain two symmetrical aromatic ring connected to the core, thus giving a 'butterfly" like appearance. A variety of aromatic rings have been reported including, quinolinium, triazole, benzimidazole, and substituted phenyl rings. Linkers like urea, benzene, diketene, pyridine, benzene are attached to the core. Due to their flexible rotation of the linkers, they can adapt different structural conformation so that they can fit into groove and loops of G4, thus showing higher binding affinity to G4.

First reported bis-aryl compounds were bis-quinolinium triazines (compound 12459) ${ }^{101}$. These compounds show low cytotoxicity and acts as a potent human telomerase inhibitor $\left({ }^{\text {tel }} \mathrm{IC}_{50}=\right.$ $0.13 \mu \mathrm{M})^{102}$. Later derivatives of bisquinolinium compounds with a pyridodicarboxamide (PDC) core (e.g. Compounds 360A) were synthesized and these compounds were found to be 100 times more selective to G4 than duplex DNA ${ }^{103}$. Internal syn-syn hydrogen bond favours these ligands to interact G4 with high selectivity. Later Phen-DC derivatives (Figure 4) were 
synthesized with an expanded aromatic core,by replacing pyridine with bipyridine or phenanthroline and showing higher selectivity and specificity towards G4 than duplex DNA ${ }^{104}$. Phen DC derivatives also exhibit anti-telomerase activity with ${ }^{\text {tel }} \mathrm{IC}_{50}$ value of $0.3 \mu \mathrm{M}$.

Ligands with diarylurea skeleton are extensively studied due to their drug like characteristics.These ligands contains 1,2,3-triazole rings attached to a diphenyl urea moiety ${ }^{105}$. These ligands can orient themselves by locating urea oxygen atom over the ion channel and allowing deep penetration of the side chains into G4 grooves by triazole-phenyl bond rotation thus stabilizing G-quartet more efficiently by $\pi$-stacking interactions. Further modelling studies suggested that the ortho- and meta-substituted analogues are optimal for G4 DNA affinity as they can adopt a "square-planar" conformation, than that of the para-substituted ligands which are sterically too large for optimal interaction with the G-quartet. Also, the formation of an intramolecular H-bond, ortho-substituted analogues are conformationally constrained by the urea NH and the triazole-N3 atom, which enforces the desired "square-planar" conformation ${ }^{105}$. Due to the presence of three rotatable bonds in the scaffold, triphenylpyridine is one of the most rigid and diverse skeletons as G4 ligand. The side chains positioned by central core help to discriminate different G4 loops. Compounds with two amine chains linked directly to the aryl rings, with piperazine(N-Ppz) substituents confers specificity and the highest affinity to human telomeric and c-KIT2 G4 DNA, but they failed to discriminate between them significantly. From the data of different substitution reaction, suggests that the protonation of the amine is critical. According to FRET study, compounds with a para-thiomethylphenyl or para-bromophenyl substituent on the central pyridine ring and four carbon atom length side chains, confers the highest stability and specificity towards all G4 DNA sequences reported till date over dsDNA. Compounds containing thiophene, furan and piperonal units exhibit much higher specificity for G4 over dsDNA but with moderate stabilization and also ligands 
with alkyl amine phenyl ether, bulky benzyl ether and para-dimethylaminophenyl 4substituents on the central pyridine present the poorest G4 stabilization.

\section{Oxazole derivatives}

Telomestatin (SOT-095), a macrocyclic natural product that was isolated from Streptomyces annulatus 3533- SV4 in 2001 by Shin ya et al, which consists of seven oxazole rings and one thiazoline ring and this is currently the most effective in-vitro telomerase inhibitor, with an ${ }^{\text {tel }} \mathrm{IC}_{50}$ value of $5 \mathrm{nM}$ obtained from TRAP assay ${ }^{106}$. This compound selectively binds to intramolecular G4 rather than intermolecular quadruplex and specific to G4 than duplex DNA with more than 70-fold preference. Molecular dynamics study confirmed that telomestatin overlaps with four guanine residues by the help of stacking interaction onto it thus stabilizing the G4 at a greater extent. Anti-proliferative role of telomestatin has been reported from wide range of cancer cell lines like breast cancer $^{107}$, myeloid leukaemia ${ }^{108}$, human pancreatic carcinoma ${ }^{109}$ etc. Later, telomestatin has also been used to stabilizes and to throw light on the biological roles of other G4es formed at the promoter regions of various oncogenes like, $B C L 2^{110}, c-M Y C^{111}, V E G F^{29}$ etc. But above all it has some disadvantages too, as telomestatin is hard to get in large quantities and huge effort is needed in large scale synthesis. Furthermore, due to its low solubility in water, delivery of the drug became difficult.

But recently hexaoxazole macrocyles, composed of two symmetric trioxazoles linked by amino acids, such as, valine (HXDV) and bistrioxazole acetate have been synthesized by Rice et $\mathrm{al}^{112,113}$. Due to its telomestatin-like concave shape, HXDV has been reported to show high specificity towards G4 by entropically driven 'terminal capping' binding mode and not to duplex or triplex DNA. To make this hexaoxazole macrocycles more water soluble, amino acid linkers are modified and HXDL are synthesized by changing a valine residue to lysine. HXDL interacts with G4 with higher affinity because of positively charged amine groups of lysine at 
physiological $\mathrm{pH}^{114}$. Hexa-oxazole with an arginine linker was also been synthesized and found telomestatin like activity. On the other hand, bistrioxazole acetates, having a macrocyclic bisamide structure, were synthesized with a ${ }^{\text {tel }} \mathrm{IC}_{50}=2 \mu \mathrm{M}^{115}$.

\section{Porphyrin derivatives}

Porphyrins are one of the most well studied binding agents for duplex DNA by intercalating interaction. The aromatic rings of porphyrin give them a planar arrangement and thus binds to the G4s too by stacking interaction with the $\mathrm{G}$ tetrads. Porphyrins have four $\mathrm{N}$-methylated pyridines. Water solubility and $\pi-\pi$ stacking interactions are increased by the polycationic moiety due to ionic configuration and decreased electron density of the core aromatic system. Hurley et al reported TMPyP4 as the type molecule of this class (Figure 4). From CD melting analysis and NMR experiments, it has been reported that TMPyP4(tetra- (N-methyl-4pyridyl)porphyrin was found to bind both duplex DNA, parallel and antiparallel G-quadruplex structures with only two fold greater affinity for G4 than duplex DNA ${ }^{109,110,116}$. Thus, TMPyP4 showed poor selectivity for G4 over duplex DNA. Later, it was found that TMPyP4 binds and stabilizes different $\mathrm{G} 4$ in oncogenic promoters like $K-R A S, c-M Y C, B C l 2$ etc. CD melting and ITC experiments suggested that, TMPyP4 binds to $c-M Y C$ Pu27 G4 at a TMPyP4/Pu27 stoichiometry of 4:1. But, its isomer TMPyP2 (tetra-(N-methyl-2-pyridyl) porphyrin showed very weak affinity to G4s.From the NMR Chemical shift, it was clearly observed that TMPyP4 binds to G4 by stacking interaction externally. Recently, from the crystal structure of TMPyP4 and human bimolecular telomeric G4 complex, it was found that TMPyP4 stacked on TTA nucleotides either at the external loop or at the 5' region of the G4 ,involving hydrogen bonding between the base pairs, which are not taking part in the G4 formation ${ }^{117}$. As TMPyP4 is a standardized molecular skeleton to probe G4, this porphyrin skeleton is modified to increase $\mathrm{G}$ quadruplex selectivity and specificity. By replacing the cationic pyridinium ring of 
TMPyP4 with a phenol ring which possess a quaternary ammonium moiety, TQMP ,a nonpyridinium cationic porphyrin has been synthesized showing 30-fold increase in G4 selectivity than TMPyP4 through specific groove and loop binding ${ }^{118}$.

Later to increase specificity, expanded porphyrin derivative, 5,10,15,20-[tetra(N-methyl-3pyridyl)]-26,28-diselenasapphyrin chloride (Se2SAP) was synthesized and reported to bind selectively to G4 DNA with a 50-fold increase over duplex DNA ${ }^{111}$. Se2SAP was found to bind selectively to $c-M Y C$ G-quadruplex even in the presence of other quadruplexes and duplex DNA and convert parallel $c-M Y C$ quadruplex into mixed parallel and anti-parallel hybrid conformation $^{119}$. Even Se2SAP can bind and stabilize bcl-2 promoter quadruplex into mixed anti-parallel and parallel hybrid structures ${ }^{110}$. But due to the low synthetic yields this ligand failed to draw further attention. At present, pentacationic manganese (III) porphyrin, containing four flexible cationic arms attached to the central aromatic core, is the most specific ligand that can discriminate between G4 and DNA, increasing the selectivity by 10,000 folds $^{120}$. Other TMPyP4 variants, such as , cationic $N$-confused porphyrin ${ }^{80,121}$, pyridyl-substituted corrole ${ }^{122}$, porphyrazines $^{123}$ and phthalocyanines have been recently reported. Among them, Tetramethylpyridinium porphyrazines (TMPyPz), nonsymmetrical phthalocyanine azo derivatives, was found to show higher binding affinity (by 100 fold) to human telomeric G4 than duplex DNA by 100 fold as compared with TMPyP4 ${ }^{123}$. Zinc complex (Zn-TMPyPz) derivatives was found to show similar affinity and selectivity ${ }^{124}$. Later water soluble octacationic zinc phthalocyanine $(\mathrm{ZnPc})$ was also found to be an effective G-quadruplex binding ligand with anti-telomerase activity $\left({ }^{\text {tel }} \mathrm{IC}_{50}=0.23 \mu \mathrm{M}\right)^{124}$.

\section{Quinacridine analogues}

In 2001, Mergny et al reported a new class of crescent shaped dibenzophenanthroline (quinacridine) pentacyclic ligands containing five fused aromatic rings in a linear arrangement and extended amino side chains that increase the propensity of overlapping with the G-quartet 
and electrostatic interaction with grooves ${ }^{125}$. Many quinacridine derivatives, including MOQ (mono ortho quinacridine) and MMQ (mono meta quinacridine) were already synthesized and CD melting studies suggest that these ligands bind to the human intramolecular quadruplex and having anti-telomerase activity ${ }^{126}$. The two active compounds like disubstituted quinacridines (Figure 5) and cyclo-bis-quinacridine BOQ have $\Delta \mathrm{T}_{\mathrm{M}}$ values of 19.7 and $12.5^{\circ} \mathrm{C}$, and $\mathrm{IC}_{50}$ values of 0.028 and $0.5 \mu \mathrm{m}$, respectively ${ }^{127}$. Cyclic bis-quinacridine (BOQ1), scaffold is mainly composed of two quinacridines connected by polyamine linkers, having greater quadruplex selectivity than mono-quinacridine compounds. BQQ1 binds to $\mathrm{G} 4$ preferentially $\left(\Delta \mathrm{T}_{\mathrm{M}}\right.$ $=+28^{\circ} \mathrm{C}$ ) than that of duplex DNA, due to the steric hindrance effect of the macro-cyclic scaffold which makes it more favourable groove/loop interactions. Thus BQQ1 appears as one of the most potential drug scaffold targeting G4.Recently, a novel platinum-quinacridine hybrid (PtMPQ) composed of single functional Pt moiety and mono-para-quinacridine, was reported to interact with quadruplex DNA by a dual covalent- noncovalent binding mode ${ }^{128}$.

\section{Berberine derivatives}

Berberine, a plant alkaloid (Figure 4), was first isolated from Chinese herbs and reported to have anti-microbial activity but later it was established as a G4 stabilizing agent too. In 1999, berberine was reported to have anti-telomerase activity ${ }^{129}$ and many 13 -substituted berberine derivatives are synthesized by Neidle et al. These derivatives bind to G4 with very high affinity ${ }^{130}$. They also found that piperidino-berberine has better stabilizing effect on Gquadruplex and increased anti-telomerase activity. Huang et al. synthesized 9-subsituted berberines having an alkyl side chain with a terminal amino group, which can efficiently interact G4 with greater binding affinity than berberine. 9-subsitituted berberines are again 
modified by the incorporation of one extra pyridine ring on berberine scaffold and thus, quinolino-benzo dihydroisoquindolium (QBDI) compounds (Figure 4) are synthesized, which have enhanced G4 interacting potential due to the increased aromaticity of the QBDI backbone. Later, it was reported that these 9-substituted berberine and QBDI derivatives possess higher selectivity for G-quadruplex DNA in $c-M Y C$ oncogene than the others.

\section{Quindoline derivatives}

Molecular modelling study of anthraquinones and acridines derivatives revealed that a tricyclic chromophore is not specific for stacking interaction to G-quartet terminal. The disubstituted derivatives (Figure 5) of the natural product quindoline with two alkyl amino groups at the 2,7-positions or at the 2,10-positions, showed ${ }^{\text {tel }} \mathrm{IC}_{50}$ values in the range of $6-16 \mu \mathrm{M}^{131}$ and another class of tetracyclic chromophore ligands containing four aromatic rings, benzo[b]naphtho [2,3-d]furan have been reported to have ${ }^{\text {tel }} \mathrm{IC}_{50}$ value of $7.0 \mu \mathrm{M}$. Another report suggests that 11 -subsitituted quindolines show stronger anti-telomerase activity than the disubstituted quindolines, with ${ }^{\text {tel }} \mathrm{IC}_{50}$ values of $0.4-12 \mu \mathrm{M}^{132}$ due to the presence of the nitrogen atom in the pyridine ring of quindoline. Substituted amino groups at the 11-position act as electron-donating groups which can enhance the basicity of the pyridine nitrogen atom $^{132}$. This nitrogen atom in the pyridine ring can be protonated at physiological $\mathrm{pH}$, thus increasing the electrostatic interaction between the positively charged quindoline scaffold and the negatively charged centre of the G4. This 11-substituted quindoline also triggers G-rich sequence in $c-M Y C$ promoter to fold into a G4 and downregulate their cellular expressions ${ }^{133}$.

\section{Polyamides}


Distamycin A (Dist-A) (Figure 5) is a highly studied antibiotic which binds to the narrow, deep A/T sequence of the minor groove of B-DNA because of its curved helical polyamide structure. It binds to duplex DNA in a drug/DNA stoichiometry of 2: $1^{134}$. Later, it has been reported that Dist-A interacts with diverse array of parallel G-quadruplex sequences. In 2007, Randazzo et al reported the NMR structure of Dist-A/[d(TGGGGT)]4 complex and found that two dimers are formed by four Dist-A molecules binds to two opposite grooves of the quadruplex through the interaction with G-quartets and sugar-phosphate backbone by the help of $\pi-\pi$ stacking interaction. It also achieves a dipole-dipole interaction between G4 and the pyrrole ring and the carbonyl group of Dist- $\mathrm{A}^{135}$. Different polyamides have been synthesized by using distamycin scaffold. Amide-linked oligopyrroles, 2,4 and 2,5-pyrrole polyamides show selectivity towards duplex DNA than G4 but selectivity towards G4 increased in these molecules by changing the heterocyclic skeleton ${ }^{136}$. These ligands show anti cell proliferative activity in human lung carcinoma (A549), human colorectal carcinoma (HT29) and then against breast cancer with $\mathrm{IC}_{50}$ values in very low micromolar range ${ }^{137}$.

\section{Perylene, Coronene and Napthalene Diimide}

Perylene is one of the most suitable G4 binding ligands due to its electron-rich polyaromacity and flat geometry. By the help of molecular docking studies, Hurley et al. synthesized PIPER (Figure 5) compounds based on the perylene scaffold with ${ }^{\text {tel }} \mathrm{IC}_{50}$ values in the low- $\mu \mathrm{M}$ range $^{138}$. NMR study indicates that PIPER binds to many G4 structures in 1: 1, 1: 2, or 2: 1 stoichiometric ratios ${ }^{139}$. Later, PIPER derivatives were synthesized by the modification of the aromatic core and side chain lengths. Protonated or alkylated amino groups of the side chains increases the binding affinity with G4. Further incorporation of cationic side chains [DAPER4C $(1,6)]$ made hydrophobic perylene system more water soluble ${ }^{140}$. 
Coronene is another polyaromatic system used as a ligand. Many coronene derivatives were also synthesized, which can stabilize G4 DNA. They also had anti-telomerase activity ${ }^{141}$. Later, many naphthalene diimides substitutes were synthesized by incorporating DNA alkylating groups by flexible spacers to increase G4 selectively ${ }^{142}$. The hydrophobic planar core of these molecules stacks on to G4 and the additional ionic interactions with the loops are increased due to the alkylated amino side chains.

\section{(C) Ligands conjugated with peptides, nucleotides and glycosides}

G4 specificity and selectivity has been increased by incorporating additional structural motifs such as peptides, nucleotides and glycosides. These conjugates helped to specifically discriminate among different conformations of G4. Among them synthetic peptide-ligand conjugates are extensively studied. Specific tetrapeptides like RKKV, KRSR, and FRHR were tethered to the side chains of acridine ligands which shows higher affinity and specificity towards G4 over duplex DNA by interacting with the quadruplex loops ${ }^{143-145}$.

NCQ, a neomycin (aminogylcoside) capped macrocycles was reported to bind G4 by interacting with the G-quartet and the loop by the formation of hydrogen bonds between base pairs and the amino and hydroxyl groups of neomycin ${ }^{146}$. Later it was found that NCQ specifically binds to loop-containing G4 than non-loop containing G4s. An open neomycinperylene conjugate has also been reported recently with both base stacking and groove binding intaerction $^{147}$.

Acridine-oligonucleotide conjugates were also designed and found to interact with both single stranded telomeric sequences and G4 structure $^{148}$. Several peptide nucleic acids (PNA) were also synthesized ${ }^{149}$. Acridone scaffold was modified by conjugating peptide containing guanine repeats and found to interact with single-stranded fragment of telomeric DNA, forming a $(1+3)$ hybrid quadruplex ${ }^{149}$. Oligonucleotide conjugates interact with both external surface of G4 and its central scaffold. Thus, such ligand conjugates serve as an efficient G4 binding 
scaffold for better recognition, higher specificity and improved solubility. Above all, it is necessary to choose the right biomolecules for designing future ligand conjugates with higher bioavailability, biocompatibility and lower cytotoxic effects.

\section{(D) Peptide selective to G-quadruplex:}

Apart from other biologics (Protein and DNA) peptide offer an attractive therapeutic potential that could be used to target G4. Peptide mimics as a protein and interacts sturdily and selectively with its target quadruplex. Being smaller sized it is non-immunogenic, and its ease of synthesis permits it to be synthesized in industrial quantity. Peptides are also non-toxic and present combinatorial chemistry allows the development of series of peptide having wealth of therapeutic potential. Though the research with developing anti-cancer peptide that targets G4 is at a pre-mature stage, still some worthwhile work has been carried out.

Jana et al. reported that LL37 (Table 2), a human cathelicidin antimicrobial peptide, which has different immunological function, is a binder of G4 ${ }^{150}$. LL37 selectively binds and stabilizes the human telomeric G-quadruplex structures and downregulate telomerase activity. The LL37 peptide binds to G-quadruplex with 10-fold selectivity over duplex DNA. Four different telomeric sequences, P1 [TAGGG(TTAGGG)3TT], P2 [GGG(TTAGGG)3T], P3 [GGG(TTAGGG)3TT], P4 [TAGGG(TTAGGG)3] are chosen and the binding affinity of the G quadruplex with LL37 was found in the order P4 > P3 > P1 > P2. Molecular Dynamics simulation studies showed that Arg7 and Arg23 are the two important residues of LL37 which mainly interacts the negatively charged phosphate backbone of G-quadruplexes, thus stabilizing it and probably pushes proliferating cells towards apoptosis. But since LL37 is a large protein it is cell membrane impermeable also the binding affinity of LL37 towards Gquadruplex is too weak for it to become a viable drug. 
To address these issues, our group had truncated the quadruplex binding domain of LL37 and made some selective mutations to increase the affinity towards $c-M Y C$ G4 developing a peptide molecule, KR12C (Table 2), which is highly specific to previously undruggable c-MYC G4 and stabilize it by $9^{\circ} \mathrm{C}$ as observed from Circular Dichroism melting experiment. We also observed binding affinity $\left(K_{\mathrm{D}}\right)$ of the peptide to the $\mathrm{c}-M Y C \mathrm{G} 4$ is $901 \mathrm{nM}^{151}$ through Isothermal titration Calorimetry, in the presence of MCF-7 nuclear extract (which mimicked a molecular crowding condition). $\mathrm{KR} 12 \mathrm{C}$ was involved in a multitude of electrostatic and weaker $\mathrm{CH} 3-\pi$ interactions to impart selectivity and stability to MYC G4 structure. The guanidino group of R12 attaches to the sugar phosphate backbone of by electrostatic interaction. Similarly, the penultimate R2 at N-terminus clings to the sugar-phosphate backbone of 5 ' end of MYC G4 ${ }^{151}$. These two connections were extremely steady as experimented from Molecular Dynamics Simulation. They protected the G-quartet proximal to 5'-terminus by gripping the backbone of the guanines delineating the quartet. Furthermore, L11 and I7 came into spatial proximity of the terminal quartet and stabilized the Hoogsteen hydrogen bonding between via $\mathrm{CH} 3-\pi$ interactions ${ }^{151}$. This peptide also downregulates c-MYC transcription by $\sim 5$ fold ${ }^{151}$. The peptide achieved this feat by binding to the G4 and depleting the occupancy of both NM23-H2 and Nucleolin.

Kobayashi et al also developed a peptide library to check interaction of the peptides with various quadruplexes by electrophoresis. He generated two series of peptides with the hope to find NRAS/cMYC/WNT/FGF G4 specific peptide. He added varied amino acids to the Nterminus of the KWK motif with the hope to vary aromatic character $(\mathrm{H}, \mathrm{W}, \mathrm{F}$, or Y), flexibility of the main chain $(\mathrm{G}$ or $\mathrm{P})$ and charge of the peptide $(\mathrm{K} \text { or } \mathrm{E})^{152}$. It was found that peptide 003 , 007 and 015 binds specifically to WNT G4 binder $^{152}$ and peptide 010 binds to $c-M Y C$ G4 $4^{152}$. They furthered their study with the peptide 010 and found that it increases TM of MYC G4 by $8^{\circ} \mathrm{C}$ and that of $F G F \mathrm{G} 4$ by $4^{\circ} \mathrm{C}^{152}$. Circular Dichroism study reported that 010 is a parallel 
quadruplex specific binder. Though specific studies with these peptides are yet to be done work by Kobayashi gives an excellent start point.

So, to summarize the G4 interacting peptide must have an aromatic amino acid to stack to quadruplex and must be positively charged so that it can pass through the cell membrane easily and interact with the phosphate backbone of DNA. But one major drawback of peptide is that they are susceptible to peptidases/proteases in body ${ }^{153}$. But it can be evaded by using several mechanisms like blocking the $\mathrm{C}$ - and $\mathrm{N}$ - termini, using D-amino acids, and chemical modifications improving their pharmacodynamic and pharmacokinetic profiles ${ }^{153,154}$.

\section{Conclusion:}

Playing a major role in regulating gene expression, G-quadruplex has become a striking anticancer target. As quadruplex offer a varied biological function, targeting them has become an attractive area of drug discovery research. A fresh perspective to these motifs has led to the development of ligands that interact with these structures. In this review, we have seen that there are several small molecules developed against G4 structures. But with exception to quarfloxin none has made it till clinical trial. In-fact most of the small molecules fails to distinguish between different quadruplexes and show selectivity to more than one G4. Since G-Quadruplex have high polymorphic and flexible conformation it is difficult to design ligand that can detect and interact with these structures. The major drawback of small molecule as a quadruplex targeting drug is its off-target effect and toxicity. Sometimes these molecules degrade to produce toxic metabolite and show low body clearance. All these drawbacks must be addressed to develop a molecule as a drug. To be a G4 targeting drug any molecule must follow the following condition- (1). It must distinguish quadruplex from duplex and bind to it. (2). It must discriminate between different G-Quadruplexes. (3). It should have low off-target effect. (4). It must be cell-penetrable and (5). It must not degrade to toxic metabolite in cell. 
Still a molecule which checks all these criteria is yet to be discovered. Despite the presence of several therapeutic drug against cancer, multi drug resistance nature of cancer played a doom over conventional treatment. Therefore, drug discovery calls for an alternative treatment and this is why conjugative molecules and peptide as a drug is flourishing. Slowly researchers are focusing more to derive G4 stabilizing peptide. Present combinatorial chemistry and phage display library technique allows one to evaluate multiple peptide against a target and select best from the lot ${ }^{155,156}$ in one go. Since peptide can fold back and forth on their own, they are able to modify themselves according to changing G4 landscape while binding to them providing more selectivity and tight binding.

The ill-fated drawbacks that make G4 an elusive target can be handled by incorporating bioinformatics and computational approach which can lead to the discovery and development of more novel ligand that can distinguish varied topology of G4 with much more stringency ${ }^{157}$. Adopting structure-based drug design and ligand screening from a virtual database ${ }^{158}$ is a next step to ensure that one gets a ligand that is selective to a quadruplex. NMR and X-ray crystal structure of G-Quadruplex-ligand complex has shed light onto the atomic interactions that take place between them and this information can be harnessed to develop more potent drug ${ }^{159,160}$. Though there is still no G4 targeting ligand which can be used as a drug, G4 directed therapy is at a rise given its importance in cancer and other disease. Current research and generation of new techniques is mining out wealth of knowledge about the G4 structures and it is not long till we find next-generation G4 targeting ligands with higher therapeutics and lower cytotoxicity.

\section{Reference:}

1. Bochman, M.L., Paeschke, K. \& Zakian, V.A. DNA secondary structures: stability and function of G-quadruplex structures. Nature reviews. Genetics 13, 770-780 (2012). 
2. Hansel-Hertsch, R., Di Antonio, M. \& Balasubramanian, S. DNA G-quadruplexes in the human genome: detection, functions and therapeutic potential. Nature reviews. Molecular cell biology 18, 279-284 (2017).

3. Bhattacharyya, D., Mirihana Arachchilage, G. \& Basu, S. Metal Cations in G-Quadruplex Folding and Stability. Frontiers in chemistry 4, 38-38 (2016).

4. Rhee, S., Han Zj Fau - Liu, K., Liu K Fau - Miles, H.T., Miles Ht Fau - Davies, D.R. \& Davies, D.R. Structure of a triple helical DNA with a triplex-duplex junction.

5. Tateishi-Karimata, H., Kawauchi, K. \& Sugimoto, N.A.-O. Destabilization of DNA GQuadruplexes by Chemical Environment Changes during Tumor Progression Facilitates Transcription.

6. Neidle, S. \& Parkinson, G. Telomere maintenance as a target for anticancer drug discovery.

7. Ding, Y., Fleming, A.M. \& Burrows, C.J. Case studies on potential G-quadruplex-forming sequences from the bacterial orders Deinococcales and Thermales derived from a survey of published genomes.

8. Song, J., Perreault, J.P., Topisirovic, I. \& Richard, S. RNA G-quadruplexes and their potential regulatory roles in translation.

9. Rouleau, S., Glouzon, J.S., Brumwell, A., Bisaillon, M. \& Perreault, J.P. 3' UTR G-quadruplexes regulate miRNA binding.

10. Weldon, C., et al. Specific G-quadruplex ligands modulate the alternative splicing of Bcl-X.

11. Beaudoin, J.D. \& Perreault, J.P. Exploring mRNA 3'-UTR G-quadruplexes: evidence of roles in both alternative polyadenylation and mRNA shortening.

12. Huppert, J.L. \& Balasubramanian, S. G-quadruplexes in promoters throughout the human genome. Nucleic acids research 35, 406-413 (2007).

13. Eddy, J. \& Maizels, N. Gene function correlates with potential for G4 DNA formation in the human genome.

14. Arthanari, H. \& Bolton, P.H. Functional and dysfunctional roles of quadruplex DNA in cells.

15. Shammas, M.A. Telomeres, lifestyle, cancer, and aging. Current opinion in clinical nutrition and metabolic care 14, 28-34 (2011).

16. Lim, K.W., et al. Structure of the human telomere in K+ solution: a stable basket-type Gquadruplex with only two G-tetrad layers.

17. Luu, K.N., Phan At Fau - Kuryavyi, V., Kuryavyi V Fau - Lacroix, L., Lacroix L Fau - Patel, D.J. \& Patel, D.J. Structure of the human telomere in K+ solution: an intramolecular $(3+1) \mathrm{G}$ quadruplex scaffold.

18. Takahama, K., et al. Regulation of telomere length by G-quadruplex telomere DNA- and TERRA-binding protein TLS/FUS.

19. Lin, C. \& Yang, D. Human Telomeric G-Quadruplex Structures and G-Quadruplex-Interactive Compounds.

20. Picard, F., et al. The Spatiotemporal Program of DNA Replication Is Associated with Specific Combinations of Chromatin Marks in Human Cells. PLOS Genetics 10, e1004282 (2014).

21. Kruisselbrink, E., et al. Mutagenic capacity of endogenous G4 DNA underlies genome instability in FANCJ-defective C. elegans.

22. Picard, F., et al. The spatiotemporal program of DNA replication is associated with specific combinations of chromatin marks in human cells.

23. Valton, A.L., et al. G4 motifs affect origin positioning and efficiency in two vertebrate replicators.

24. Huppert, J.L. \& Balasubramanian, S. G-quadruplexes in promoters throughout the human genome.

25. Brooks, T.A. \& Hurley, L.H. Targeting MYC Expression through G-Quadruplexes.

26. Dexheimer, T.S., Sun D Fau - Hurley, L.H. \& Hurley, L.H. Deconvoluting the structural and drugrecognition complexity of the G-quadruplex-forming region upstream of the bcl-2 P1 promoter. 
27. Rankin, S., et al. Putative DNA quadruplex formation within the human c-kit oncogene.

28. Cogoi, S. \& Xodo, L.E. G-quadruplex formation within the promoter of the KRAS protooncogene and its effect on transcription.

29. Sun, D., Guo K Fau - Rusche, J.J., Rusche Jj Fau - Hurley, L.H. \& Hurley, L.H. Facilitation of a structural transition in the polypurine/polypyrimidine tract within the proximal promoter region of the human VEGF gene by the presence of potassium and G-quadruplex-interactive agents.

30. $\mathrm{Xu}, \mathrm{Y}$. \& Sugiyama, H. Formation of the G-quadruplex and i-motif structures in retinoblastoma susceptibility genes $(\mathrm{Rb})$.

31. Qin, Y., Rezler Em Fau - Gokhale, V., Gokhale V Fau - Sun, D., Sun D Fau - Hurley, L.H. \& Hurley, L.H. Characterization of the $\mathrm{G}$-quadruplexes in the duplex nuclease hypersensitive element of the PDGF-A promoter and modulation of PDGF-A promoter activity by TMPyP4.

32. Chaires, J.B., et al. An improved model for the hTERT promoter quadruplex.

33. , i-302.

34. Sun, D., et al. The proximal promoter region of the human vascular endothelial growth factor gene has a G-quadruplex structure that can be targeted by G-quadruplex-interactive agents.

35. Duquette, M.L., Handa P Fau - Vincent, J.A., Vincent Ja Fau - Taylor, A.F., Taylor Af Fau Maizels, N. \& Maizels, N. Intracellular transcription of G-rich DNAs induces formation of Gloops, novel structures containing G4 DNA.

36. Cho, S.S. Computational and Experimental Characterization of Ribosomal DNA and RNA GQuadruplexes. Biophysical Journal 110, 566a (2016).

37. Drygin, D., et al. Anticancer activity of CX-3543: a direct inhibitor of rRNA biogenesis.

38. Capra, J.A., Paeschke K Fau - Singh, M., Singh M Fau - Zakian, V.A. \& Zakian, V.A. G-quadruplex DNA sequences are evolutionarily conserved and associated with distinct genomic features in Saccharomyces cerevisiae.

39. Schaffitzel, C., et al. \&lt;em\&gt;In vitro\&lt;/em\&gt; generated antibodies specific for telomeric guanine-quadruplex DNA react with \&lt;em\&gt;Stylonychia lemnae \&lt;/em\&gt;macronuclei. Proceedings of the National Academy of Sciences 98, 8572 (2001).

40. Biffi, G., Tannahill, D., McCafferty, J. \& Balasubramanian, S. Quantitative visualization of DNA G-quadruplex structures in human cells. Nature chemistry 5, 182-186 (2013).

41. Artusi, S., et al. Visualization of DNA G-quadruplexes in herpes simplex virus 1-infected cells. Nucleic Acids Research 44, 10343-10353 (2016).

42. Kudlicki, A.S. G-Quadruplexes Involving Both Strands of Genomic DNA Are Highly Abundant and Colocalize with Functional Sites in the Human Genome. PloS one 11, e0146174-e0146174 (2016).

43. Murat, P. \& Balasubramanian, S. Existence and consequences of G-quadruplex structures in DNA. Current Opinion in Genetics \& Development 25, 22-29 (2014).

44. Chen, M.C., et al. Structural basis of G-quadruplex unfolding by the DEAH/RHA helicase DHX36.

45. Fedoroff, O.Y., et al. NMR-Based model of a telomerase-inhibiting compound bound to Gquadruplex DNA.

46. Han, H., Cliff Cl Fau - Hurley, L.H. \& Hurley, L.H. Accelerated assembly of G-quadruplex structures by a small molecule.

47. Yao, X., et al. Interaction between G-Quadruplex and Zinc Cationic Porphyrin: The Role of the Axial Water.

48. Sabater, L., et al. Cobalt(III)porphyrin to target G-quadruplex DNA.

49. Tawani, A., Mishra, S.K. \& Kumar, A.A.-O.h.o.o. Structural insight for the recognition of Gquadruplex structure at human c-myc promoter sequence by flavonoid Quercetin.

50. Ruggiero, E. \& Richter, S.N. G-quadruplexes and G-quadruplex ligands: targets and tools in antiviral therapy. Nucleic Acids Research 46, 3270-3283 (2018). 
51. Adrian, M., Winnerdy, F.R., Heddi, B. \& Phan, A.T. Rotation of Guanine Amino Groups in GQuadruplexes: A Probe for Local Structure and Ligand Binding.

52. Murat, P., Singh Y Fau - Defrancq, E. \& Defrancq, E. Methods for investigating G-quadruplex DNA/ligand interactions.

53. Calabrese, D.R., et al. Chemical and structural studies provide a mechanistic basis for recognition of the MYC G-quadruplex.

54. Chen, Y. \& Yang, D. Sequence, stability, and structure of G-quadruplexes and their interactions with drugs.

55. Young, A.J.A.-O.h.o.o. The role of telomeres in the mechanisms and evolution of life-history trade-offs and ageing. LID - 20160452 [pii] LID - 10.1098/rstb.2016.0452 [doi].

56. Hahn, W.C., et al. Creation of human tumour cells with defined genetic elements.

57. Burger, A.M., et al. The G-quadruplex-interactive molecule BRACO-19 inhibits tumor growth, consistent with telomere targeting and interference with telomerase function.

58. Read, M.A., et al. Molecular modeling studies on G-quadruplex complexes of telomerase inhibitors: structure-activity relationships.

59. Ruggiero, E. \& Richter, S.N. G-quadruplexes and G-quadruplex ligands: targets and tools in antiviral therapy.

60. De Cian, A., et al. Reevaluation of telomerase inhibition by quadruplex ligands and their mechanisms of action.

61. Saha, D., et al. Epigenetic suppression of human telomerase (hTERT) is mediated by the metastasis suppressor NME2 in a G-quadruplex-dependent fashion.

62. Micheli, E., Martufi M Fau - Cacchione, S., Cacchione S Fau - De Santis, P., De Santis P Fau Savino, M. \& Savino, M. Self-organization of G-quadruplex structures in the hTERT core promoter stabilized by polyaminic side chain perylene derivatives.

63. Vogelstein, B., et al. Cancer genome landscapes.

64. Huang, F.W., et al. Highly recurrent TERT promoter mutations in human melanoma.

65. Xing, M., et al. BRAF V600E and TERT promoter mutations cooperatively identify the most aggressive papillary thyroid cancer with highest recurrence.

66. Gomez, D., et al. Telomerase downregulation induced by the G-quadruplex ligand 12459 in A549 cells is mediated by hTERT RNA alternative splicing.

67. Douarre, C., et al. DNA damage signaling induced by the G-quadruplex ligand 12459 is modulated by PPM1D/WIP1 phosphatase.

68. Certo, M., et al. Mitochondria primed by death signals determine cellular addiction to antiapoptotic BCL-2 family members.

69. Marshall, K.A., Daniel Se Fau - Cairns, N., Cairns N Fau - Jenner, P., Jenner P Fau - Halliwell, B. \& Halliwell, B. Upregulation of the anti-apoptotic protein $\mathrm{Bcl}-2$ may be an early event in neurodegeneration: studies on Parkinson's and incidental Lewy body disease.

70. Satou, T., Cummings Bj Fau - Cotman, C.W. \& Cotman, C.W. Immunoreactivity for Bcl-2 protein within neurons in the Alzheimer's disease brain increases with disease severity.

71. Kuhlmann, T., et al. Bcl-2-expressing oligodendrocytes in multiple sclerosis lesions.

72. Sengupta, P., Chattopadhyay, S. \& Chatterjee, S. G-Quadruplex surveillance in BCL-2 gene: a promising therapeutic intervention in cancer treatment.

73. Amato, J.A.-O.h.o.o., et al. Targeting the BCL2 Gene Promoter G-Quadruplex with a New Class of Furopyridazinone-Based Molecules.

74. Asif, M. Some recent approaches of biologically active substituted pyridazine and phthalazine drugs.

75. Jana, J., et al. Chelerythrine down regulates expression of VEGFA, BCL2 and KRAS by arresting G-Quadruplex structures at their promoter regions.

76. Hu, M.H., et al. Discovery of a New Four-Leaf Clover-Like Ligand as a Potent c-MYC Transcription Inhibitor Specifically Targeting the Promoter G-Quadruplex. 
77. Yang, F., et al. Selective recognition of c-myc promoter G-quadruplex and down-regulation of oncogene c-myc transcription in human cancer cells by 3,8a-disubstituted indolizinone. RSC Advances 7, 51965-51969 (2017).

78. Lavrado, J., et al. KRAS oncogene repression in colon cancer cell lines by G-quadruplex binding indolo[3,2-c]quinolines.

79. Ray, P., Krishnamoorthy N Fau - Ray, A. \& Ray, A. Emerging functions of c-kit and its ligand stem cell factor in dendritic cells: regulators of T cell differentiation.

80. Zorzan, E., et al. Screening of candidate G-quadruplex ligands for the human c-KIT promotorial region and their effects in multiple in-vitro models.

81. Morrell, A., et al. Nitrated indenoisoquinolines as topoisomerase I inhibitors: a systematic study and optimization.

82. Morrell, A., et al. Optimization of the indenone ring of indenoisoquinoline topoisomerase I inhibitors.

83. Bejugam, M., et al. Targeting the c-Kit Promoter G-quadruplexes with 6-Substituted Indenoisoquinolines.

84. Sabouri, N., Capra, J.A. \& Zakian, V.A. The essential Schizosaccharomyces pombe Pfh1 DNA helicase promotes fork movement past G-quadruplex motifs to prevent DNA damage.

85. Derenzini, M., et al. Nucleolar size indicates the rapidity of cell proliferation in cancer tissues.

86. Rickards, B., Flint Sj Fau - Cole, M.D., Cole Md Fau - LeRoy, G. \& LeRoy, G. Nucleolin is required for RNA polymerase I transcription in vivo.

87. Hanakahi, L.A., Sun H Fau - Maizels, N. \& Maizels, N. High affinity interactions of nucleolin with G-G-paired rDNA.

88. Hurwitz, H., et al. Bevacizumab plus irinotecan, fluorouracil, and leucovorin for metastatic colorectal cancer.

89. Sandler, A., et al. Paclitaxel-carboplatin alone or with bevacizumab for non-small-cell lung cancer.

90. Escudier, B., et al. Sorafenib in advanced clear-cell renal-cell carcinoma.

91. Wu, Y., et al. Stabilization of VEGF G-quadruplex and inhibition of angiogenesis by quindoline derivatives.

92. Cammas, A., et al. Stabilization of the G-quadruplex at the VEGF IRES represses capindependent translation.

93. Sun, D., et al. Inhibition of Human Telomerase by a G-Quadruplex-Interactive Compound. Journal of Medicinal Chemistry 40, 2113-2116 (1997).

94. Perry, P.J., et al. 2,7-Disubstituted Amidofluorenone Derivatives as Inhibitors of Human Telomerase. Journal of Medicinal Chemistry 42, 2679-2684 (1999).

95. Harrison, R.J., Gowan, S.M., Kelland, L.R. \& Neidle, S. Human telomerase inhibition by substituted acridine derivatives. Bioorg Med Chem Lett 9, 2463-2468 (1999).

96. Haider, S.M., Parkinson, G.N. \& Neidle, S. Structure of a G-quadruplex-ligand complex. J Mol Biol 326, 117-125 (2003).

97. Harrison, R.J., et al. Trisubstituted Acridine Derivatives as Potent and Selective Telomerase Inhibitors. Journal of Medicinal Chemistry 46, 4463-4476 (2003).

98. Moore, M.J.B., et al. Trisubstituted Acridines as G-quadruplex Telomere Targeting Agents. Effects of Extensions of the 3,6- and 9-Side Chains on Quadruplex Binding, Telomerase Activity, and Cell Proliferation. Journal of Medicinal Chemistry 49, 582-599 (2006).

99. Burger, A.M., et al. The G-Quadruplex-Interactive Molecule BRACO-19 Inhibits Tumor Growth, Consistent with Telomere Targeting and Interference with Telomerase Function. Cancer Research 65, 1489 (2005).

100. Bejugam, M., et al. Trisubstituted Isoalloxazines as a New Class of G-Quadruplex Binding Ligands: Small Molecule Regulation of c-kit Oncogene Expression. Journal of the American Chemical Society 129, 12926-12927 (2007). 
101. Gomez, D., et al. Resistance to the Short Term Antiproliferative Activity of the G-quadruplex Ligand 12459 Is Associated with Telomerase Overexpression and Telomere Capping Alteration. Journal of Biological Chemistry 278, 50554-50562 (2003).

102. Riou, J.F., et al. Cell senescence and telomere shortening induced by a new series of specific G-quadruplex DNA ligands. Proceedings of the National Academy of Sciences 99, 2672 (2002).

103. Lemarteleur, T., et al. Stabilization of the c-myc gene promoter quadruplex by specific ligands' inhibitors of telomerase.

104. Monchaud, D., et al. Ligands playing musical chairs with G-quadruplex DNA: a rapid and simple displacement assay for identifying selective G-quadruplex binders. Biochimie 90, 1207-1223 (2008).

105. Drewe, W.C. \& Neidle, S. Click chemistry assembly of G-quadruplex ligands incorporating a diarylurea scaffold and triazole linkers.

106. Shin-ya, K., et al. Telomestatin, a Novel Telomerase Inhibitor from Streptomyces anulatus. Journal of the American Chemical Society 123, 1262-1263 (2001).

107. Tahara, H., et al. G-Quadruplex stabilization by telomestatin induces TRF2 protein dissociation from telomeres and anaphase bridge formation accompanied by loss of the $3^{\prime}$ telomeric overhang in cancer cells. Oncogene 25, 1955 (2005).

108. Sumi, M., et al. A G-quadruplex-interactive agent, telomestatin (SOT-095), induces telomere shortening with apoptosis and enhances chemosensitivity in acute myeloid leukemia.

109. Liu, W., Sun, D. \& Hurley, L.H. Binding of G-Quadruplex-interactive Agents to Distinct GQuadruplexes Induces Different Biological Effects in MiaPaCa Cells. Nucleosides, Nucleotides and Nucleic Acids 24, 1801-1815 (2005).

110. Dexheimer, T.S., Sun, D. \& Hurley, L.H. Deconvoluting the Structural and Drug-Recognition Complexity of the G-Quadruplex-Forming Region Upstream of the bcl-2 P1 Promoter. Journal of the American Chemical Society 128, 5404-5415 (2006).

111. Seenisamy, J., et al. Design and Synthesis of an Expanded Porphyrin That Has Selectivity for the c-MYC G-Quadruplex Structure. Journal of the American Chemical Society 127, 2944-2959 (2005).

112. Minhas, G.S., Pilch, D.S., Kerrigan, J.E., LaVoie, E.J. \& Rice, J.E. Synthesis and G-quadruplex stabilizing properties of a series of oxazole-containing macrocycles. Bioorg Med Chem Lett 16, 3891-3895 (2006).

113. Barbieri, C.M., et al. Defining the mode, energetics and specificity with which a macrocyclic hexaoxazole binds to human telomeric G-quadruplex DNA. Nucleic Acids Research 35, 32723286 (2007).

114. Rzuczek, S.G., Pilch Ds Fau - LaVoie, E.J., LaVoie Ej Fau - Rice, J.E. \& Rice, J.E. Lysinyl macrocyclic hexaoxazoles: synthesis and selective G-quadruplex stabilizing properties.

115. Tera, M., et al. Design and Synthesis of Telomestatin Derivatives and Their Inhibitory Activity of Telomerase. ChemInform 38(2007).

116. Wheelhouse, R.T., Sun, D., Han, H., Han, F.X. \& Hurley, L.H. Cationic Porphyrins as Telomerase Inhibitors: the Interaction of Tetra-(N-methyl-4-pyridyl)porphine with Quadruplex DNA. Journal of the American Chemical Society 120, 3261-3262 (1998).

117. Phan, A.T., Kuryavyi, V., Gaw, H.Y. \& Patel, D.J. Small-molecule interaction with a five-guaninetract G-quadruplex structure from the human MYC promoter. Nature chemical biology 1, 167173 (2005).

118. Wang, P., et al. A Phenol Quaternary Ammonium Porphyrin as a Potent Telomerase Inhibitor by Selective Interaction with Quadruplex DNA. ChemBioChem 7, 1155-1159 (2006).

119. Freyer, M.W., et al. Biophysical Studies of the c-MYC NHE III1 Promoter: Model Quadruplex Interactions with a Cationic Porphyrin. Biophysical Journal 92, 2007-2015 (2007).

120. Dixon, I.M., et al. A G-Quadruplex Ligand with 10000-Fold Selectivity over Duplex DNA. Journal of the American Chemical Society 129, 1502-1503 (2007). 
121. Du, $\mathrm{Y}$., et al. Cationic N-confused porphyrin derivative as a better molecule scaffold for Gquadruplex recognition.

122. Ma, H., et al. Pyridyl-Substituted Corrole Isomers: Synthesis and their Regulation to Gquadruplex Structures. Chemistry - An Asian Journal 5, 114-122 (2009).

123. Gonçalves, D.P.N., Rodriguez, R., Balasubramanian, S. \& Sanders, J.K.M. Tetramethylpyridiniumporphyrazines-a new class of G-quadruplex inducing and stabilising ligands. Chemical Communications, 4685-4687 (2006).

124. Ren, L., et al. Quaternary Ammonium Zinc Phthalocyanine: Inhibiting Telomerase by Stabilizing G quadruplexes and Inducing G-Quadruplex Structure Transition and Formation. ChemBioChem 8, 775-780 (2007).

125. Mergny, J.L., et al. Telomerase inhibitors based on quadruplex ligands selected by a fluorescence assay. Proc Natl Acad Sci U S A 98, 3062-3067 (2001).

126. Hounsou, C., et al. G-Quadruplex Recognition by Quinacridines: a SAR, NMR, and Biological Study. ChemMedChem 2, 655-666 (2007).

127. Mergny, J.-L., et al. Telomerase inhibitors based on quadruplex ligands selected by a fluorescence assay. Proceedings of the National Academy of Sciences 98, 3062 (2001).

128. Bertrand, H., Bombard S Fau - Monchaud, D., Monchaud D Fau - Teulade-Fichou, M.-P. \& Teulade-Fichou, M.P. A platinum-quinacridine hybrid as a G-quadruplex ligand.

129. Naasani, I., Seimiya, H., Yamori, T. \& Tsuruo, T. FJ5002: A Potent Telomerase Inhibitor Identified by Exploiting the Disease-oriented Screening Program with COMPARE Analysis. Cancer Research 59, 4004 (1999).

130. Franceschin, M., et al. Natural and synthetic G-quadruplex interactive berberine derivatives. Bioorg Med Chem Lett 16, 1707-1711 (2006).

131. Caprio, V., et al. A novel inhibitor of human telomerase derived from $10 \mathrm{H}$-indolo[3,2b]quinoline. Bioorg Med Chem Lett 10, 2063-2066 (2000).

132. Zhou, J.M., et al. Senescence and telomere shortening induced by novel potent G-quadruplex interactive agents, quindoline derivatives, in human cancer cell lines. Oncogene 25, 503-511 (2006).

133. Ou, T.-M., et al. Stabilization of G-Quadruplex DNA and Down-Regulation of Oncogene c-myc by Quindoline Derivatives. Journal of Medicinal Chemistry 50, 1465-1474 (2007).

134. Asagi, M., Toyama, A. \& Takeuchi, H. Binding affinity and mode of distamycin A with A/T stretches in double-stranded DNA: importance of the terminal A/T residues. Biophys Chem 149, 34-39 (2010).

135. Martino, L., et al. Structural and Thermodynamic Studies of the Interaction of Distamycin A with the Parallel Quadruplex Structure [d(TGGGGT)]4. Journal of the American Chemical Society 129, 16048-16056 (2007).

136. Moore, M.J.B., Cuenca, F., Searcey, M. \& Neidle, S. Synthesis of distamycin A polyamides targeting G-quadruplex DNA. Organic \& Biomolecular Chemistry 4, 3479-3488 (2006).

137. Rahman, K.M., et al. Biaryl polyamides as a new class of DNA quadruplex-binding ligands. Chemical Communications, 4097-4099 (2009).

138. Fedoroff, O.Y., et al. NMR-Based Model of a Telomerase-Inhibiting Compound Bound to GQuadruplex DNA. Biochemistry 37, 12367-12374 (1998).

139. Han, H., Cliff, C.L. \& Hurley, L.H. Accelerated Assembly of G-Quadruplex Structures by a Small Molecule. Biochemistry 38, 6981-6986 (1999).

140. Michelia, E., D'Ambrosiob, D., Franceschina, M. \& Savino, M. Water Soluble Cationic Perylene Derivatives as Possible Telomerase Inhibitors: The Search for Selective G-Quadruplex Targeting. Mini Reviews in Medicinal Chemistry 9, 1622-1632 (2009).

141. Franceschin, M., et al. Specific interactions with intra- and intermolecular G-quadruplex DNA structures by hydrosoluble coronene derivatives: A new class of telomerase inhibitors. Bioorganic \& Medicinal Chemistry 15, 1848-1858 (2007). 
142. Hampel, S.M., Sidibe, A., Gunaratnam, M., Riou, J.-F. \& Neidle, S. Tetrasubstituted naphthalene diimide ligands with selectivity for telomeric G-quadruplexes and cancer cells. Bioorg Med Chem Lett 20, 6459-6463 (2010).

143. Ladame, S., et al. Tetrapeptides induce selective recognition for G-quadruplexes when conjugated to a DNA-binding platform. Organic \& Biomolecular Chemistry 2, 2925-2931 (2004).

144. Schouten, J.A., Ladame, S., Mason, S.J., Cooper, M.A. \& Balasubramanian, S. G-QuadruplexSpecific Peptide-Hemicyanine Ligands by Partial Combinatorial Selection. Journal of the American Chemical Society 125, 5594-5595 (2003).

145. Redman, J.E., et al. Recognition and discrimination of DNA quadruplexes by acridine-peptide conjugates. Organic \& Biomolecular Chemistry 7, 76-84 (2009).

146. Kaiser, M., et al. Neomycin-capped aromatic platforms: quadruplex DNA recognition and telomerase inhibition. Organic \& Biomolecular Chemistry 4, 1049-1057 (2006).

147. Xue, L., Ranjan, N. \& Arya, D.P. Synthesis and Spectroscopic Studies of the Aminoglycoside (Neomycin)-Perylene Conjugate Binding to Human Telomeric DNA. Biochemistry 50, 28382849 (2011).

148. Casals, J., et al. Directing Quadruplex-Stabilizing Drugs to the Telomere: Synthesis and Properties of Acridine-Oligonucleotide Conjugates. Bioconjugate Chemistry 17, 1351-1359 (2006).

149. Paul, A., Sengupta, P., Krishnan, Y. \& Ladame, S. Combining G-Quadruplex Targeting Motifs on a Single Peptide Nucleic Acid Scaffold: A Hybrid $(3+1)$ PNA-DNA Bimolecular Quadruplex. Chemistry - A European Journal 14, 8682-8689 (2008).

150. Jana, J., et al. Human cathelicidin peptide LL37 binds telomeric G-quadruplex.

151. Sengupta, P., et al. Site-specific amino acid substitution in dodecameric peptides determines the stability and unfolding of c-MYC quadruplex promoting apoptosis in cancer cells.

152. Use of a Designed Peptide Library to Screen for Binders to a Particular DNA G-Quadruplex Sequence. Journal of Nucleic Acids 2011(2011).

153. Thundimadathil, J. Cancer Treatment Using Peptides: Current Therapies and Future Prospects. Journal of Amino Acids 2012, 13 (2012).

154. Borghouts, C., Kunz C Fau - Groner, B. \& Groner, B. Current strategies for the development of peptide-based anti-cancer therapeutics.

155. Fosgerau, K. \& Hoffmann, T. Peptide therapeutics: current status and future directions.

156. Molek, P., Strukelj B Fau - Bratkovic, T. \& Bratkovic, T. Peptide phage display as a tool for drug discovery: targeting membrane receptors.

157. Zhang, D.H., et al. Monomorphic RNA G-quadruplex and polymorphic DNA G-quadruplex structures responding to cellular environmental factors.

158. Musumeci, D., et al. Tandem application of ligand-based virtual screening and G4-OAS assay to identify novel G-quadruplex-targeting chemotypes.

159. Campbell, N.H., Parkinson Gn Fau - Reszka, A.P., Reszka Ap Fau - Neidle, S. \& Neidle, S. Structural basis of DNA quadruplex recognition by an acridine drug.

160. Parkinson, G.N., Cuenca F Fau - Neidle, S. \& Neidle, S. Topology conservation and loop flexibility in quadruplex-drug recognition: crystal structures of inter- and intramolecular telomeric DNA quadruplex-drug complexes. 
Figure 1: Structural organization of G-Quadruplex stabilized by incorporation of metal ions $\left(\mathrm{K}^{+}, \mathrm{Na}^{+}\right.$etc $)$in the center of the tetrad.

Figure 2: Role of G-Quadruplex in-vivo depending on its occurrence. (A). In Replication origin and promoter (B). In 5' end of mRNA (C). In 3' end of mRNA.

Figure 3: Schematic representation of oncogene specific G-Quadruplex binding ligands.

Figure 4: Chemical skeleton of some important G-Quadruplex binding ligands.

Figure 5: Chemical skeleton of some important G-Quadruplex binding ligands. 
Figure 1.

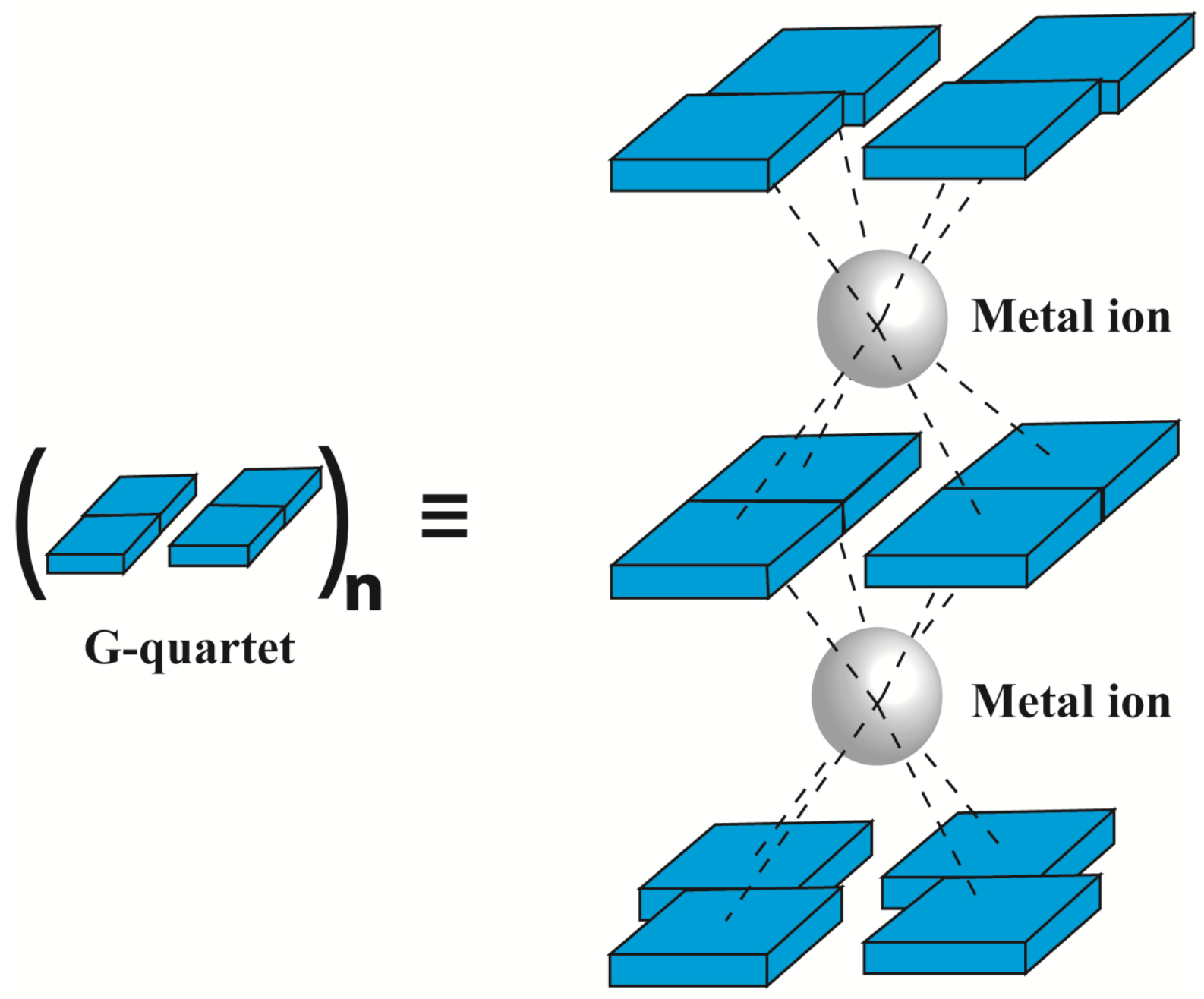

G-quadruplex 
Figure 2.

(A)

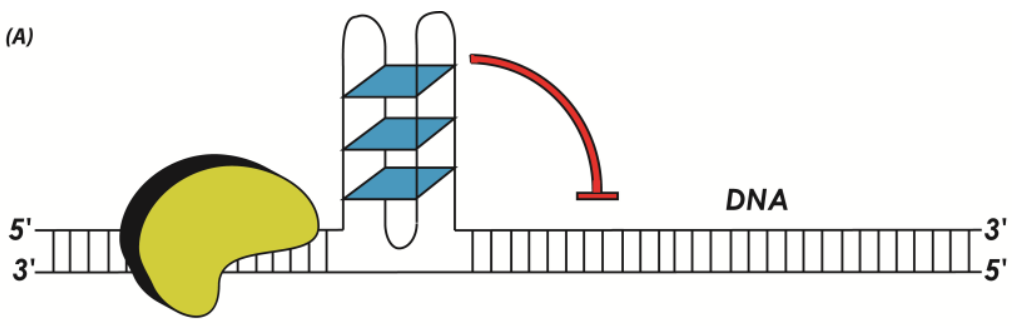

Stalling of DNA/RNA Polymerase

(B)

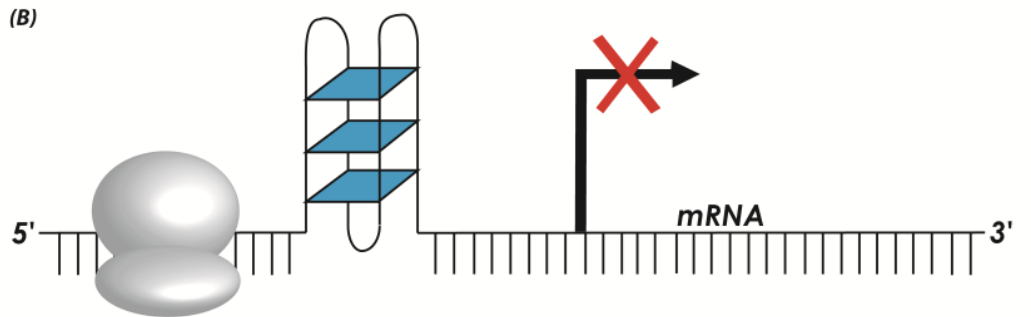

Stalling of Ribosome

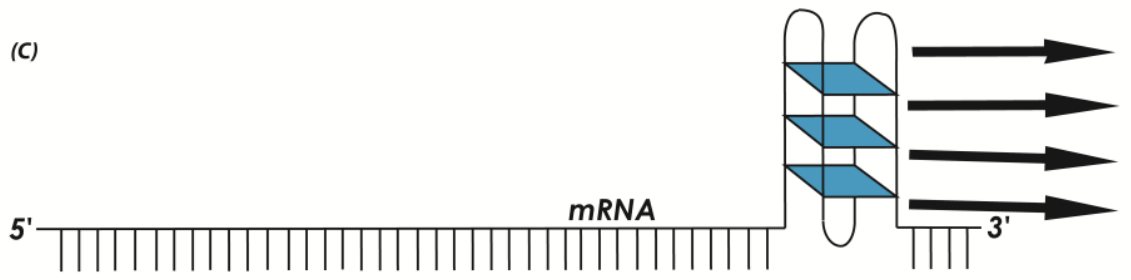

miRNA Binding

mRNA Localization

Alternative Splicing

Alternative Polyadenylation

Translation Inhibition

Replication/Transcription Inhibition

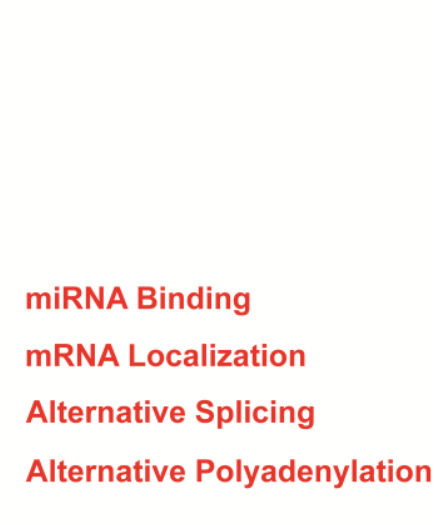


Figure 3.

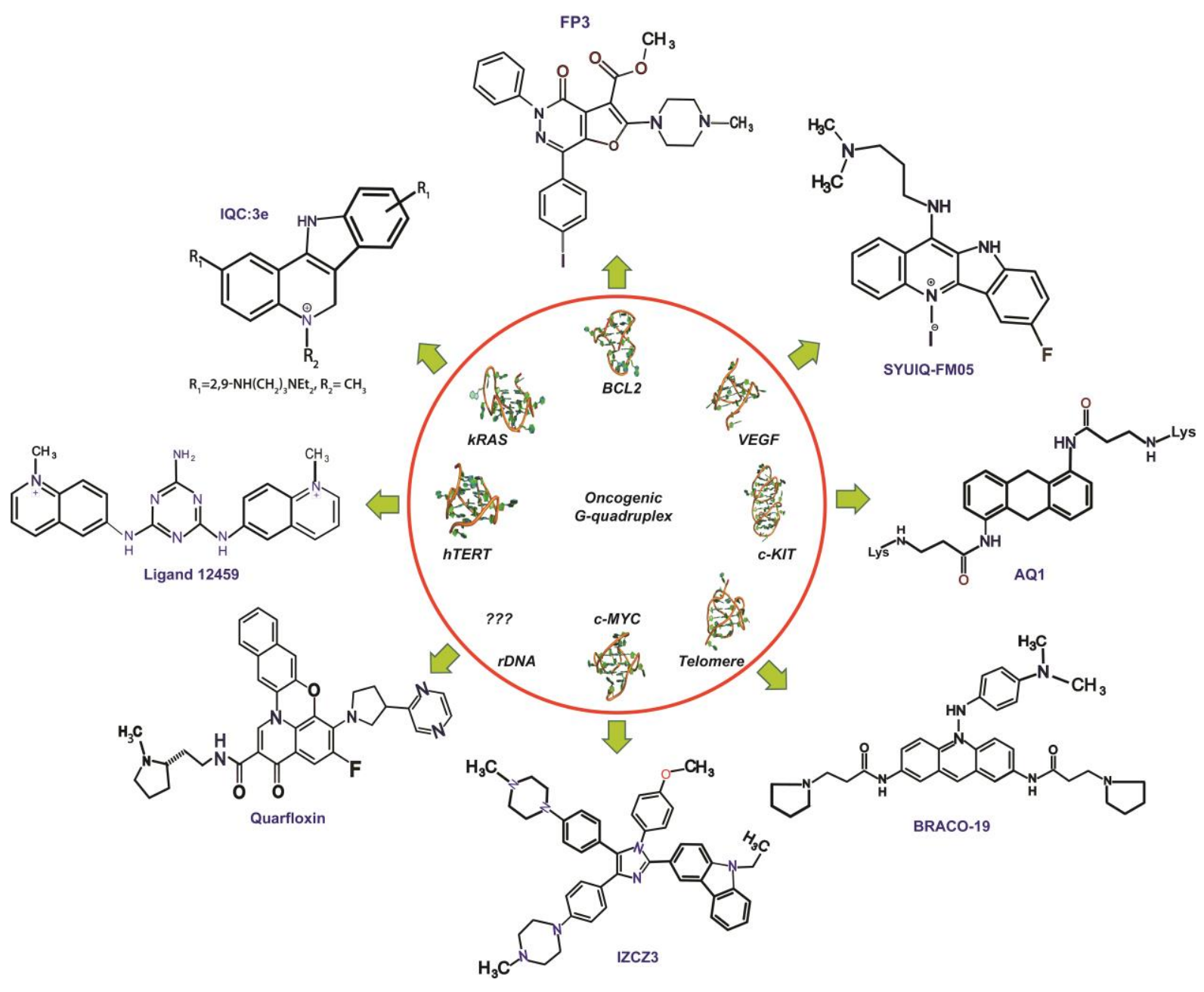


Figure 4.

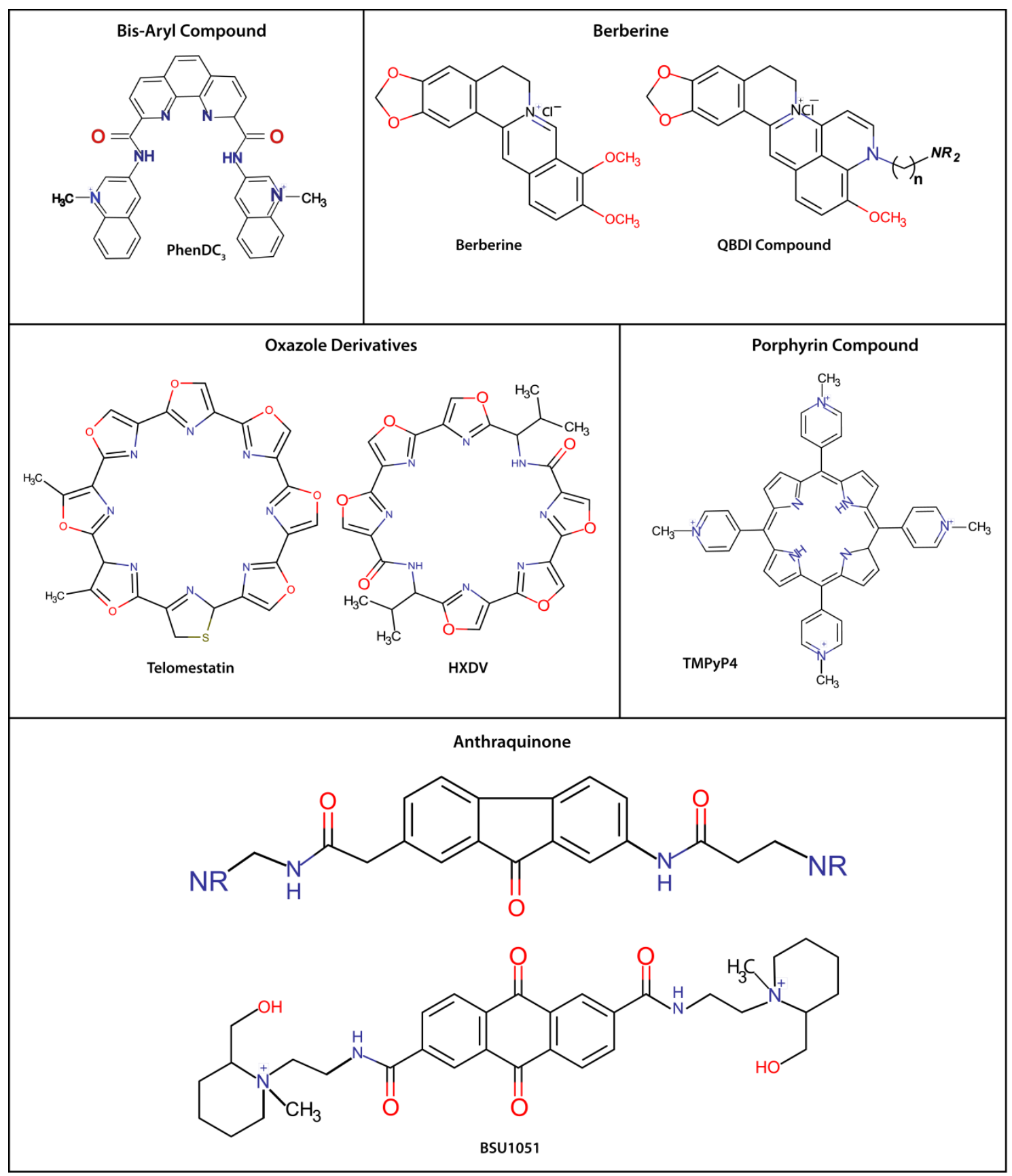




\section{Figure 5.}

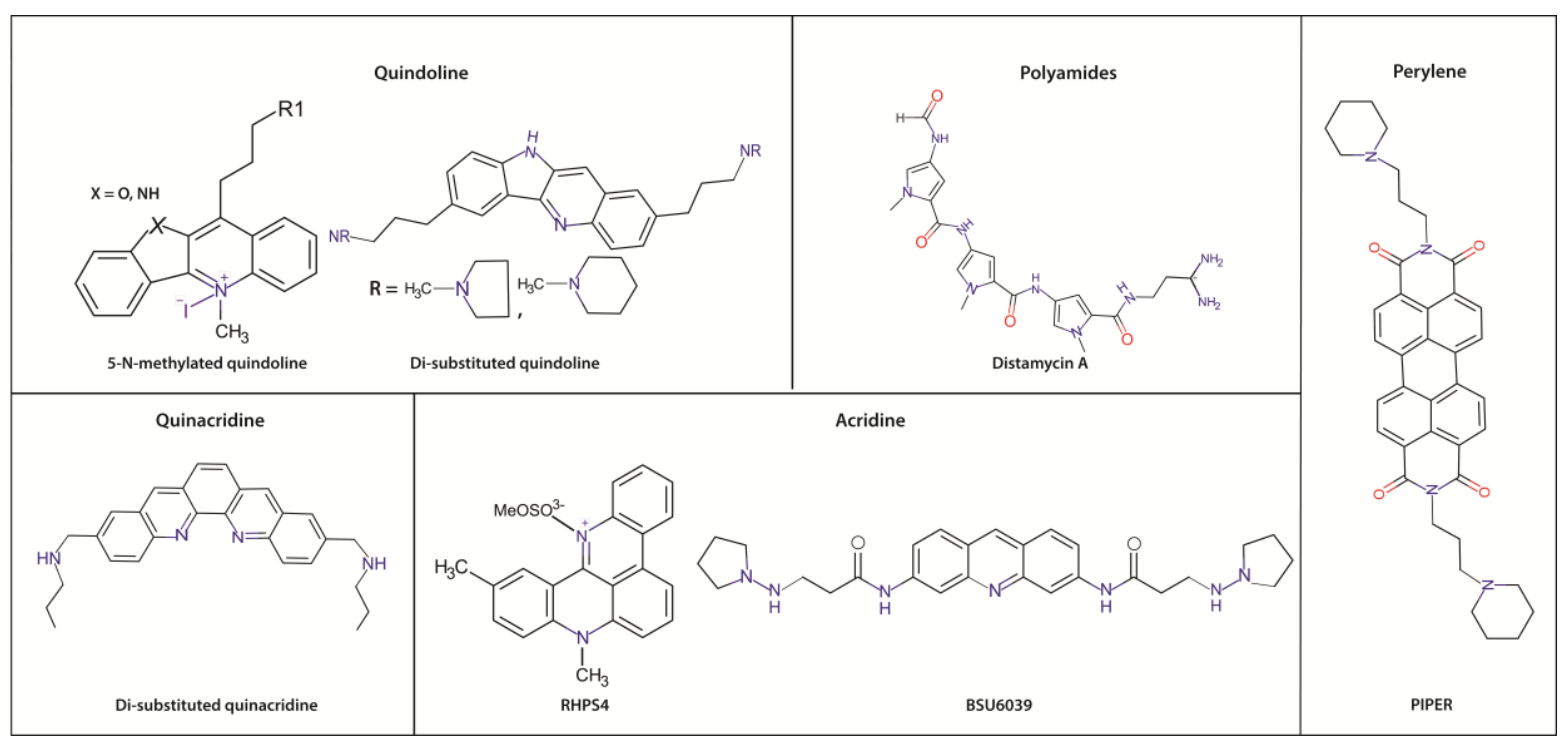


Table 1: Some important G4 binding ligands

\begin{tabular}{|c|c|c|c|c|}
\hline No & LIGAND/CHEMICAL SKELETON & $\begin{array}{l}\text { BINDING } \\
\text { MODE }\end{array}$ & $\begin{array}{l}\text { PROTONATION } \\
\text { TYPE }\end{array}$ & $\begin{array}{c}\text { tel } \mathrm{IC}_{50} \\
(\mu \mathrm{M})\end{array}$ \\
\hline 1. & TMPyP4, Cationic porphyrin & $\begin{array}{l}\text { Stacking } \\
\text { Interaction }\end{array}$ & $\begin{array}{l}\mathrm{N} \text {-methylated } \\
\text { aromatic }\end{array}$ & 8.9 \\
\hline 2. & $\begin{array}{c}\text { Telomestatin, HXDV-Cyclic } \\
\text { polyamines }\end{array}$ & $\begin{array}{l}\text { Stacking } \\
\text { Interaction }\end{array}$ & Natural Macrocycles & 0.005 \\
\hline 3. & $\begin{array}{c}\text { Acridine, RHPS4, } \\
\text { Polycyclic Methyl Acridinium }\end{array}$ & $\begin{array}{l}\text { Stacking } \\
\text { Interaction }\end{array}$ & $\begin{array}{l}\mathrm{N} \text {-methylated } \\
\text { aromatic }\end{array}$ & 0.33 \\
\hline 4. & $\begin{array}{c}\text { BSU-1051, } \\
\text { Anthraquinones }\end{array}$ & $\begin{array}{l}\text { Threading } \\
\text { intercalation }\end{array}$ & $\begin{array}{c}\text { N-methylated } \\
\text { aromatic }\end{array}$ & 23 \\
\hline 5. & BSU6039, BRACO-19, Acridines. & $\begin{array}{c}\text { Interaction } \\
\text { with grooves, } \\
\text { Stacking } \\
\text { interaction }\end{array}$ & Protonated in situ & $0.01-0.02$ \\
\hline 6. & $\begin{array}{l}\text { MOQ(monomer), } \\
\text { BOQ1(dimer), } \\
\text { Quinacridines }\end{array}$ & $\begin{array}{l}\text { groove/loop } \\
\text { interactions, } \\
\text { Stacking } \\
\text { interaction } \\
\end{array}$ & Protonated in situ & $0.028,0.137$ \\
\hline 7. & $\begin{array}{c}\text { PIPER, } \\
\text { Perylene } \\
\text { tetracarboxylic } \\
\text { diimide }\end{array}$ & $\pi-\pi$ interaction & Protonated in situ & 20 \\
\hline 8. & $\begin{array}{l}\text { Naphthalene } \\
\text { diimide }\end{array}$ & $\begin{array}{l}\text { Stacking } \\
\text { interaction }\end{array}$ & Protonated in situ & 0.05 \\
\hline 9. & $\begin{array}{c}\text { Se2SAP, } \\
\text { di-selenasapphyrin }\end{array}$ & $\begin{array}{c}\text { Stacking } \\
\text { Interaction }\end{array}$ & $\begin{array}{l}\mathrm{N} \text {-methylated } \\
\text { aromatic }\end{array}$ & - \\
\hline 10. & Pentacationic Mn (III) porphyrin & $\pi-\pi$ stacking & $\begin{array}{l}\text { N-methylated } \\
\text { aromatic, } \\
\text { metal center }\end{array}$ & 0.58 \\
\hline
\end{tabular}


Table 2: Designer peptides as a G4 targeted ligand

\begin{tabular}{|c|c|c|c|c|}
\hline No & $\begin{array}{l}\text { PEPTIDE } \\
\text { NAME }\end{array}$ & PEPTIDE SEQUENCE & $\begin{array}{c}\text { NET CHARGE } \\
\text { AT } \mathrm{PH}=7\end{array}$ & $\begin{array}{c}\text { TARGETED } \\
\text { QUADRUPLEX }\end{array}$ \\
\hline 1. & 003 & N-ter-EHKGKWK & +1.1 & WNT \\
\hline 2. & 007 & N-ter-EWKGKWK & +1 & WNT \\
\hline 3. & 015 & N-ter-EYKGKWK & +1 & WNT \\
\hline 4. & 010 & N-ter-KFEGKWK & +1 & $c-M Y C$ \\
\hline 5. & KR12C & N-ter-KRIVKLIKKWLR & +6 & $c-M Y C$ \\
\hline 6. & LL37 & N-ter-LLGDFFRKSKEKIGKEFKRIVQRIKDFLRNLVPRTES & +6 & Telomeric \\
\hline
\end{tabular}

